ARTICLE

\title{
Human cytomegalovirus-induced host protein citrullination is crucial for viral replication
}

\author{
Gloria Griffante1,2, Francesca Gugliesi (1) 1, Selina Pasquero', Valentina Dell'Oste (1) 1, Matteo Biolatti (D) 1, \\ Ari J. Salinger ${ }^{3,4}$, Santanu Mondal ${ }^{3}$, Paul R. Thompson (10 ${ }^{3}$, Eranthie Weerapana ${ }^{4}$, Robert J. Lebbink ${ }^{5}$, \\ Jasper A. Soppe ${ }^{5}$, Thomas Stamminger ${ }^{6}$, Virginie Girault (1D ${ }^{7}$, Andreas Pichlmair (1D ${ }^{7}$, Gábor Oroszlán (iD ${ }^{8}$, \\ Donald M. Coen (1) ${ }^{8}$, Marco De Andrea (i) ${ }^{1,9 凶} \&$ Santo Landolfo (iD) ${ }^{1 凶}$
}

Citrullination is the conversion of arginine-to-citrulline by protein arginine deiminases (PADs), whose dysregulation is implicated in the pathogenesis of various types of cancers and autoimmune diseases. Consistent with the ability of human cytomegalovirus (HCMV) to induce post-translational modifications of cellular proteins to gain a survival advantage, we show that HCMV infection of primary human fibroblasts triggers PAD-mediated citrullination of several host proteins, and that this activity promotes viral fitness. Citrullinome analysis reveals significant changes in deimination levels of both cellular and viral proteins, with interferon (IFN)-inducible protein IFIT1 being among the most heavily deiminated one. As genetic depletion of IFIT1 strongly enhances HCMV growth, and in vitro IFIT1 citrullination impairs its ability to bind to 5'-ppp-RNA, we propose that viral-induced IFIT1 citrullination is a mechanism of HCMV evasion from host antiviral resistance. Overall, our findings point to a crucial role of citrullination in subverting cellular responses to viral infection.

\footnotetext{
${ }^{1}$ Department of Public Health and Pediatric Sciences, University of Turin, Turin, Italy. ${ }^{2}$ Department of Translational Medicine, University of Piemonte Orientale, Novara, Italy. ${ }^{3}$ Department of Biochemistry and Molecular Pharmacology, UMass Medical School, Worcester, MA, USA. ${ }^{4}$ Department of Chemistry, Boston College, Chestnut Hill, MA, USA. ${ }^{5}$ Department of Medical Microbiology, University Medical Center Utrecht, Utrecht, The Netherlands. ${ }^{6}$ Institute of Virology, Ulm University Medical Center, Ulm, Germany. ${ }^{7}$ Institute of Virology, Technical University of Munich, Munich, Germany.

${ }^{8}$ Department of Biological Chemistry \& Molecular Pharmacology, Blavatnik Institute, Harvard Medical School, Boston, MA, USA. ${ }^{9}$ CAAD Center for

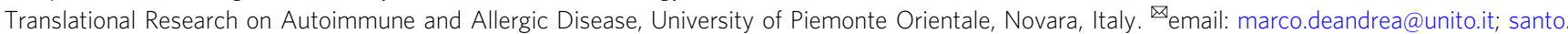
landolfo@unito.it
} 
uman cytomegalovirus (HCMV) is a $\beta$-herpesvirus infecting $40-90 \%$ of the adult human population. Even though HCMV infection is frequently harmless in healthy patients, it can lead to serious health consequences in individuals with a deficient immune system, such as transplant recipients and AIDS patients ${ }^{1}$. In addition, congenital HCMV infection is the most common cause of fetal and neonatal malformations in developed countries ${ }^{2}$. More recently, HCMV has been linked to autoimmune diseases and degenerative disorders, such as atherosclerosis, vascular disease, and immune aging as well as to certain types of tumors ${ }^{3-8}$.

One of the strategies devised by HCMV to favor its replication consists in modifying host cellular proteins at the posttranslational level, thereby altering their localization, interaction, activation, and/or turnover ${ }^{9}$.

A post-translational modification (PTM) that is increasingly recognized to play an essential role in immune-related diseases is citrullination, also called deimination, a process where the guanidinium group of arginine is hydrolyzed to form citrulline, a non-genetically encoded amino acid ${ }^{10}$. This PTM is catalyzed by the calcium-dependent protein arginine deiminase (PAD) family of enzymes, which in humans is composed of five isoforms (PADs 1-4 and 6), with different tissue-specific expression and substrate specificities ${ }^{11}$. Although aberrant citrullination has been detected in several inflammatory conditions, such as rheumatoid arthritis (RA), systemic lupus erythematosus (SLE), Alzheimer's disease (AD), multiple sclerosis (MS), Parkinson's disease, cancer, and atherosclerosis, suggesting that it may play a pathogenic role in inflammation-related diseases ${ }^{12-19}$, a direct correlation between citrullination and viral infections has only recently emerged. In particular, human rhinovirus (HRV)-induced citrullination of LL37 was found to impair the antiviral activity of this host defense protein ${ }^{20}$. Consistent with the role of citrullination in viral infections, other studies have shown how artificially citrullinated Epstein-Barr virus (EBV) proteins could be specifically recognized by RA sera ${ }^{21-23}$. Importantly, a recent in silico analysis of transcriptome datasets from lung biopsies of SARS-CoV2 -infected patients has proposed a putative role of PADs in COVID-1924.

In this study, we unveil a signature of HCMV infection based on PAD-mediated citrullination of multiple cellular proteins to disrupt host -defense mechanisms.

\section{Results}

HCMV infection induces protein citrullination. To begin to characterize protein citrullination during HCMV infection, we performed immunoblot analysis of protein lysates obtained from human foreskin fibroblasts (HFFs) infected with the HCMV strain Merlin at different time points, using the citrulline-specific probe rhodamine-phenylglyoxal $(\mathrm{Rh}-\mathrm{PG})^{25}$. We observed an increase in total protein citrullination in lysates from HCMVinfected HFFs at $48 \mathrm{~h}$ and, albeit to a lesser extent, at $96 \mathrm{~h}$ post infection (hpi) compared to uninfected control cells (mock) (Fig. 1a).

We next sought to determine whether PADs played a role in enhanced citrullination by HCMV. RT-qPCR analysis revealed that $P A D I 2,4$, and 6 genes were all expressed at significantly higher levels in HCMV-infected HFFs at 24 hpi compared to mock-infected controls (i.e., $\sim 4.8-, \sim 2.7$, and $\sim 1.7$-fold, respectively) (Fig. 1b). In particular, both PADI2 and 4 genes were upregulated at $8 \mathrm{hpi}$, reaching a peak $24 \mathrm{hpi}$ and decreasing afterward (Fig. 1c). In contrast to their mRNA expression levels, PAD2 and 4 protein levels were already increased at 24 hpi and remained elevated for up to 72 hpi (Fig. 1d), suggesting that transcription and translation of PADs are differently regulated upon HCMV infection. By contrast, the other PAD isoforms were expressed at very low (PAD3) or undetectable levels (PAD1 and 6) and did not vary following HCMV infection (Fig. 1b and Supplementary Fig. 1a), indicating that PAD2 and 4 are the only PAD enzymes involved in HCMV-induced citrullination.

PAD protein levels are induced by HCMV immediate early 1 (IE1) protein. To gain more insight into the mechanisms responsible for $P A D I 2$ and 4 transcriptional upregulation, we assessed the promoter activity of both PADI2 and 4 genes taking advantage of a dual-luciferase assay system. To this end, HFFs were transiently transfected with luciferase reporter plasmids carrying the wild-type promoter region of either PADI2 or PADI4. Twenty-four hours after electroporation, cells were infected with wild-type or UV-inactivated HCMV. UVinactivation of HCMV was confirmed by assessing its ability to produce viral immediate early antigen (IEA) compared to the intact virus (Supplementary Fig. 1b). As shown in Supplementary Fig. 1c, HCMV infection led to a robust induction of the luciferase activity driven by either the PADI2 or PADI4 promoter ( 7 - and 3.5-fold, respectively), whereas UV-HCMV infection failed to induce a similar response, indicating that the synthesis of one or more viral proteins during the initial stage of infection is critical for transcriptional activation of PADI2 and 4 genes.

We next proceeded to determine which viral gene product was responsible for the upregulation of PAD2, the most potently induced PAD member following HCMV infection (Fig. 1b, c). Treatment of HCMV-infected HFFs with the protein synthesis inhibitor cycloheximide (CHX) completely shut down HCMVinduced PAD2 protein expression at $24 \mathrm{hpi}$, attesting that de novo expression of viral proteins is required to upregulate PAD2 (Fig. 1e). Fittingly, UV-inactivated HCMV failed to induce PAD2 (Fig. 1e). In contrast, treatment with the viral DNA synthesis inhibitor phosphonoformic acid (PFA) did not seem to affect PAD2 upregulation (Fig. 1e), indicating that true late viral proteins are not involved in PAD regulation.

These results, together with the observation that the early kinetics of PAD induction (Fig. 1c) paralleled that of viral IE1 or IE2 gene expression, raised the hypothesis that IE gene products may play a functional role in PAD induction. Indeed, adenoviralmediated overexpression of IE1 (AdVIE1) but not IE2 (AdVIE2) led to a substantial upregulation of both PAD2 protein expression (Fig. 1f), indicating that IE1 is at least one of the HCMV products regulating $\mathrm{PAD}$ gene expression. Consistently, HFFs infected with a recombinant HCMV strain lacking the IE1 protein (AD169 $\mathrm{IE} 1$ ) displayed much lower levels of PAD2 protein expression at 48 hpi compared to cells transduced with the wildtype control (AD169), an effect that was reversed by AdVIE1 coinfection (Fig. $1 \mathrm{~g})^{26}$. In line with previous results, induction of citrullination by the AD169 strain was also confirmed using the citrulline-specific probe Rh-PG (Supplementary Fig. 1d).

PAD inhibition blocks HCMV replication. Next, we asked whether citrullination induced by HCMV infection would affect viral replication. To answer this question, we assessed viral plaque formation in HCMV-infected HFFs (MOI 0.1) treated for $1 \mathrm{~h}$ prior to infection with increasing concentrations of $\mathrm{Cl}$-amidine (Cl-A) (25-200 $\mu \mathrm{M})$, a cell-permeable pan-PAD inhibitor ${ }^{27}$. After 7 days of continuous exposure to $\mathrm{Cl}-\mathrm{A}$, we observed a dosedependent downregulation in the number of viral particles in HCMV-infected HFFs, with a complete suppression at $100 \mu \mathrm{M}$. Assessment of cell cytotoxicity by means of the 3-(4,5-dimethylthiazol-2-yl)-2,5-diphenyltetrazolium bromide (MTT) assay in HFFs treated under the same conditions ruled out the possibility that the antiviral activity was related to the cytotoxic effects 
a

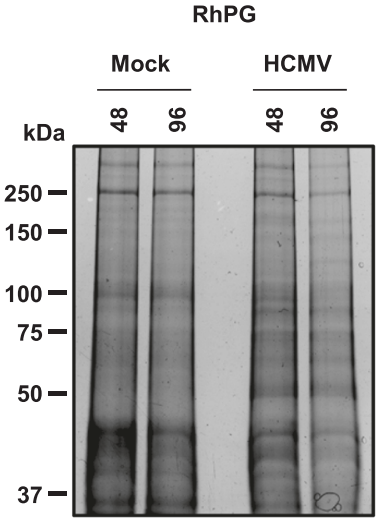

Coomassie

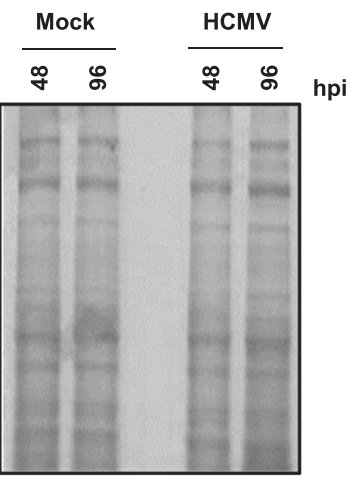

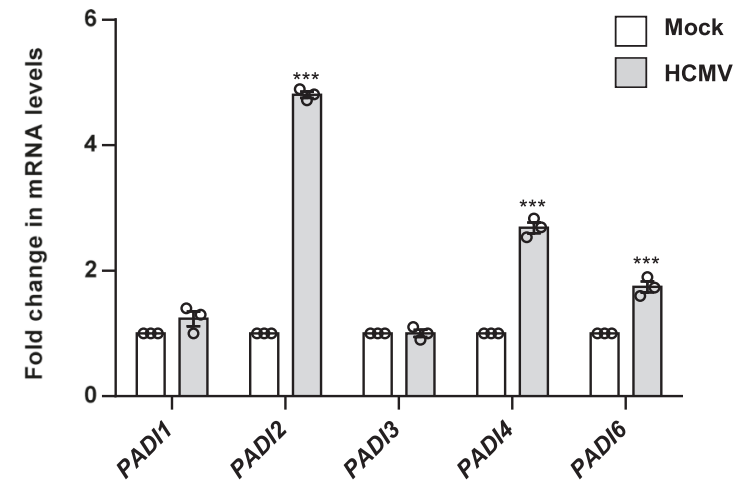

C
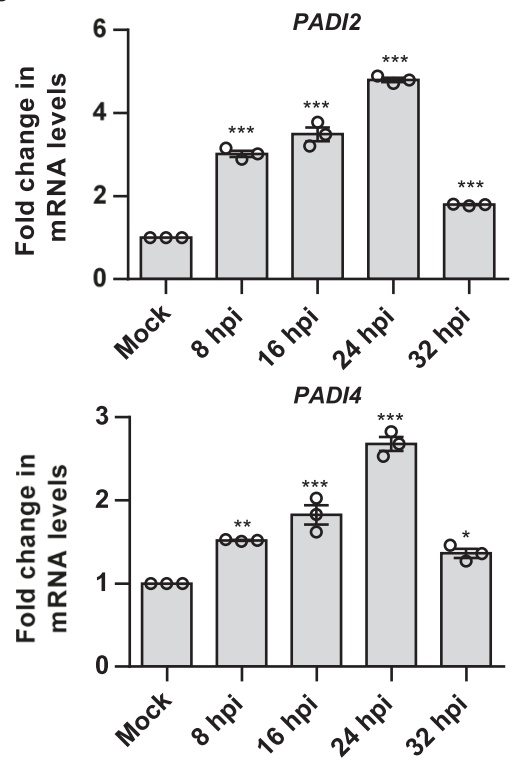

d
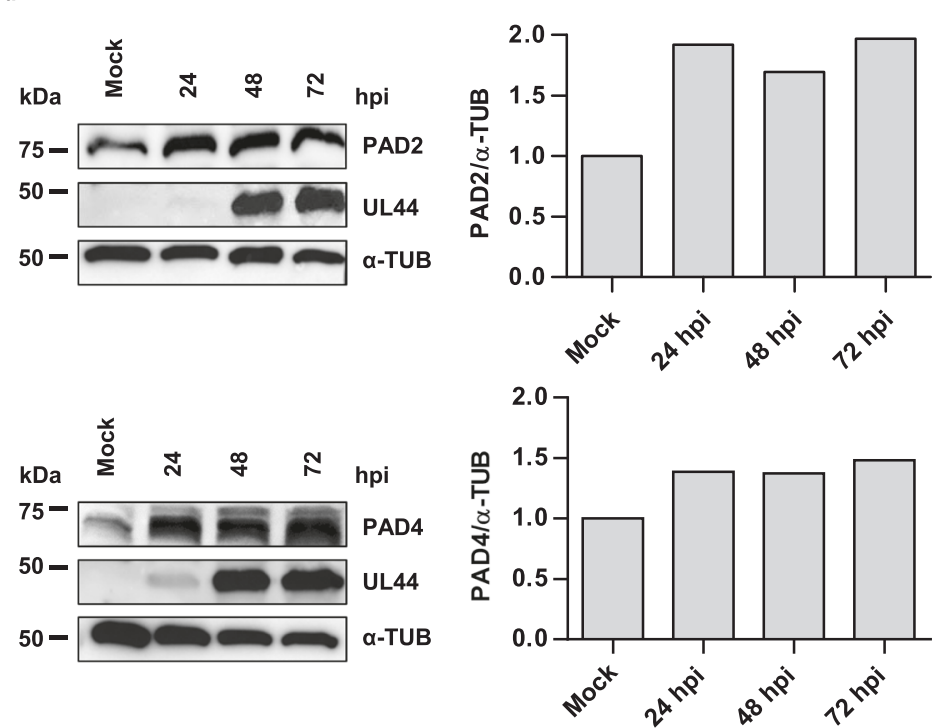

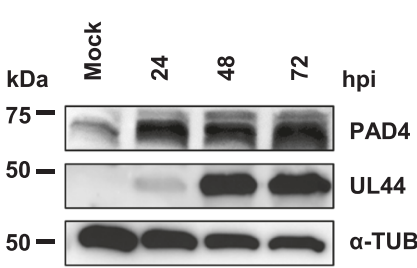

$\alpha-T U B$

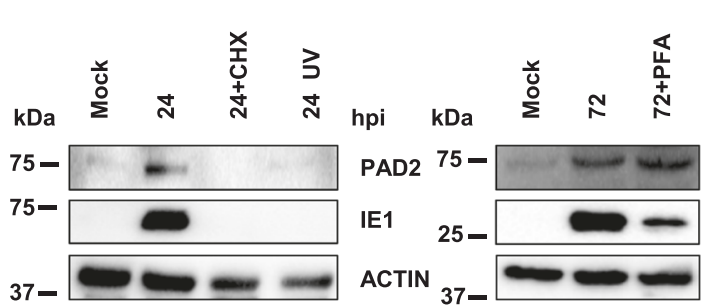

g

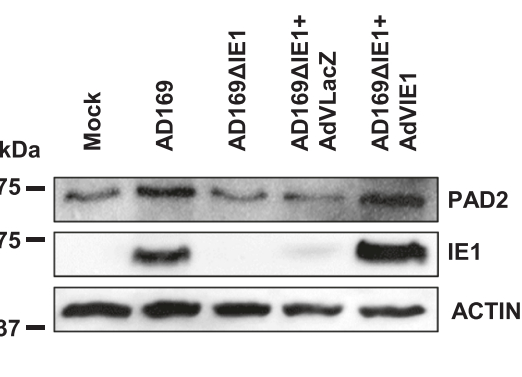

of the drug (Fig. 2a). The half-maximal inhibitory concentration $\left(\mathrm{IC}_{50}\right)$ of Cl-A was found to be $36 \mu \mathrm{M}$ (Fig. 2a). To further corroborate these data, we also measured viral DNA synthesis by quantitative real-time PCR (qPCR) in similarly treated cells. Remarkably, at the low concentration of $25 \mu \mathrm{M}$, Cl-A treatment reduced the rate of HCMV DNA replication by approximately threefold compared to untreated cells (Fig. 2b). In line with the plaque-forming activity data, treatment with $100 \mu \mathrm{M} \mathrm{Cl}-\mathrm{A}$ completely shut down HCMV DNA replication (Fig. 2b). Next, HFFs were treated for $1 \mathrm{~h}$ prior to HCMV infection with $100 \mu \mathrm{M} \mathrm{Cl}-\mathrm{A}$, infected with increasing MOI (0.01-1) of HCMV, and incubated for an additional $144 \mathrm{~h}$ in the presence of the inhibitor. At 144 hpi, the number of plaque-forming units (PFUs) was completely suppressed at MOIs ranging from 0.01 to 0.1 (Fig. 2c). Interestingly, Cl-A maintained its antiviral effect even at higher HCMV MOIs (0.5-1). Consistently, this remarkable reduction in the number of viral particles was observed also in HCMV-infected HFFs treated with BB-Cl-amidine (BB-Cl-A $)^{14}$, a secondgeneration pan-PAD inhibitor, at nontoxic concentrations much lower than $\mathrm{Cl}-\mathrm{A}$ of 1 and $0.5 \mu \mathrm{M}$, with a complete suppression at $1 \mu \mathrm{M}$ (Supplementary Fig. 2a).

To determine whether the antiviral activity of the compound was limited to HCMV or could be extended to other viruses, we assessed the effect of increasing $\mathrm{Cl}-\mathrm{A}$ concentrations on the replication of: (i) herpes simplex virus 1 (HSV-1) and 2 (HSV-2), two members of the Herpesviridae family; (ii) a clinical isolate of adenovirus as a prototype of a non-enveloped DNA virus; and (iii) the RNA virus human immunodeficiency virus 1 strain IIIb (HIV-1 $\left.1_{\text {IIIb }}\right)$. Interestingly, only HSV -1 and -2 displayed impaired viral growth in Cl-A-treated cells $\left(\mathrm{IC}_{50} \sim 66\right.$ and $\left.21 \mu \mathrm{M}\right)$ (Supplementary Fig. 2b), whereas the replication rates of adenovirus and HIV-1 $1_{\text {IIIb }}$ were only marginally affected by the 
Fig. 1 HCMV infection induces protein citrullination. a Protein lysates from HFFs infected with HCMV strain Merlin (HCMV) (MOI 1 PFU/cell) at 48 and $96 \mathrm{~h}$ post infection (hpi) or from uninfected HFFs (mock) were exposed to an Rh-PG citrulline-specific probe (left panel) and subjected to gel electrophoresis to detect citrullinated proteins. Equal loading was assessed by Coomassie blue staining (right panel). One representative gel of three independent experiments is shown. $\mathbf{b}$ mRNA expression levels of PADI isoforms by RT-qPCR of HCMV-infected (24 hpi) vs. uninfected (mock) HFFs were normalized to the housekeeping gene glyceraldehyde-3-phosphate dehydrogenase GAPDH and expressed as mean fold change \pm SEM over mock-infected cells ( $n=3$ independent determinations; PADI2, PADI4, and PADI6 $P<0.001$, two-way ANOVA followed by Bonferroni's post test). c PADI2 and PADI4 mRNA levels in HCMV-infected HFFs at the indicated time points (hpi) were normalized to GAPDH mRNA and expressed as mean fold change \pm SEM over mock-infected cells ( $n=3$ independent determinations; $P A D I 2$ : mock vs. 8 hpi $P<0.001$, mock vs. 16 hpi $P<0.001$, mock vs. 24 hpi $P<0.001$, mock vs. 32 hpi $P<0.001$; $P A D I 4$ : mock vs. 8 hpi $P=0.00375$, mock vs. 16 hpi $P<0.001$, mock vs. 24 hpi $P<0.001$, mock vs. 32 hpi $P=0.04$, one-way ANOVA followed by Bonferroni's post tests). d Western blot analysis of protein lysates from uninfected (mock) or infected HFFs using antibodies against PAD2, PAD4, UL44, or $\alpha$-tubulin ( $\alpha$-TUB). One representative blot and densitometric analysis shown of three independent experiments. Values are expressed as fold change in PAD2 and PAD4 expression normalized to $\alpha$-tubulin. e Western blot analysis of protein lysates from uninfected (mock) or infected HFFs with HCMV wild-type (HCMV), or UV-inactivated HCMV (UV) (left panel), treated with $150 \mu \mathrm{g} / \mathrm{ml} \mathrm{CHX} \mathrm{(left} \mathrm{panel)} \mathrm{at} 24 \mathrm{hpi}$, or with $250 \mu M$ PFA (right panel) at $72 \mathrm{hpi}$ or left untreated. Analysis was performed using antibodies against PAD2, IEA (recognizing IE1-72- and IE2-86 kDa), pp28, or ACTIN. One representative blot of three independent experiments is shown. $\mathbf{f}$ Western blot analysis of protein lysates from uninfected (mock), infected HFFs for $48 \mathrm{~h}$ with AdVIE1, AdVIE2, or AdVLacZ $(\mathrm{MOI}=10)$ using antibodies against IEA (recognizing IE1-72- and IE2-86 kDa), PAD2, or ACTIN. One representative blot of three independent experiments is shown. $\mathbf{g}$ Western blot analysis of protein lysates from HFFs infected with wild-type AD169 HCMV (AD169) or AD169 1 IE1 (MOI 1 PFU/cell), the latter complemented with AdVLacZ or AdVIE1 (MOI 10 PFU/cell), at 24 hpi or from uninfected HFFs (mock) using antibodies against IEA (recognizing IE1-72- and IE2-86 kDa), PAD2, or ACTIN. One representative blot of three independent experiments is shown. Data are shown as the mean \pm SEM, ${ }^{\star} P<0.05,{ }^{* \star} P<0.01,{ }^{* \star *} P<0.001$.

PAD inhibitor (Supplementary Fig. 2c). Of note, the slight reduction in adenovirus replication observed in HFFs cells treated with higher doses of $\mathrm{Cl}-\mathrm{A}$ was probably due to the cytotoxic effect of the compound, as judged by the MTT assay.

To further demonstrate that $\mathrm{Cl}-\mathrm{A}$ reduces $\mathrm{HCMV}$-driven citrullination in HFFs, we assessed total protein citrullination levels using an anti-peptidylcitrulline antibody (clone F95). In line with the results obtained with the Rh-PG probe (Fig. 1a), protein citrullination peaked at $48 \mathrm{hpi}$ and decreased at $96 \mathrm{hpi}$ (Fig. 2d). As expected, in the presence of $\mathrm{Cl}-\mathrm{A}$, protein citrullination was efficiently suppressed at either time points (Fig. 2d). Next, PAD enzymatic activity was measured by means of an in vitro antibody-based assay using histone 3 as a substrate (Fig. 2e). The reliability of the assay was first assessed using increasing amounts of human recombinant PAD2 in the presence or absence of Cl-A (Supplementary Fig. 1e). Consistent with the kinetics of PAD2 and PAD4 protein expression and with the citrullination profile, PAD catalytic activity was enhanced at 24 hpi, peaked at $48 \mathrm{hpi}$, and decreased at $72 \mathrm{hpi}$. Importantly, HCMV-induced PAD activity was significantly inhibited by $\mathrm{Cl}-\mathrm{A}$ $(100 \mu \mathrm{M})$ at 48 and $72 \mathrm{hpi}$ (Fig. 2e). Finally, to assess the extent of HCMV replication, total protein extracts from HCMV-infected HFFs treated with or without $\mathrm{Cl}-\mathrm{A}$ at various time points post infection were subjected to immunoblotting using antibodies against the corresponding IEA, early (UL44), and late (pp28) proteins. While $\mathrm{Cl}-\mathrm{A}$ treatment only marginally affected IEA expression, it inhibited the expression of viral early and late genes (Fig. 2f), indicating that PAD enzymes support the HCMV productive cycle by fostering the expression of early and late genes.

To confirm that the antiviral activity of $\mathrm{Cl}-\mathrm{A}$ was due to PAD inhibition and not to an off-target effect of the compound, we generated PAD knockout (KO) HFFs using clustered regularly interspaced short palindromic repeat (CRISPR)/Cas9 technology. Primary cell lines carrying mutations in genes encoding PAD1 (PAD1 KO), PAD2 (PAD2 KO), PAD3 (PAD3 KO), PAD6 (PAD6 KO), or PAD4 (PAD4 KO) were generated using five different guide RNAs (gRNAs). Tracking of indels by decomposition (TIDE) analysis showed an overall knockdown efficiency ranging from 35 to $45 \%$ for each of the PAD KO cell lines (Supplementary Fig. 3). Consistently, immunoblot analysis revealed a reduction in $\mathrm{PAD} 2,4$, and 3 protein expression signals between 50 and 60\% (Fig. 3a and Supplementary Fig. 4a).
With regard to PAD1 and 6, we could only rely on the aforementioned TIDE analysis (Supplementary Fig. 3) as the expression levels of these two PAD isoforms were barely detectable in HFFs, even after HCMV infection (Supplementary Fig. 1a). Although we failed to achieve total suppression of PAD gene expression, the overall knockdown efficiency proved to be sufficient enough to allow us to perform subsequent functional experiments.

To assess whether PADs are required for HCMV replication, we performed a standard plaque assay and $\mathrm{qPCR}$ as described above. As shown in Fig. 3b, c, PAD2 and PAD4 $\mathrm{KO}$ cells, respectively, displayed 0.5 and 1 logs of viral load reduction, and $\sim 60$ and $70 \%$ decrease in viral replication, at an MOI of 0.1 . In line with these results, a consistent decrease in UL44 protein expression levels was also detected in infected PAD2, and PAD4 KO cell lines at $48 \mathrm{hpi}$ (Fig. 3a). As expected, depletion of PAD1 (PAD1 KO), 3 (PAD3 KO), or 6 (PAD6 KO) in HFFs did not affect the HCMV replication rates compared to wild-type control cells (Supplementary Fig. 4b, c). Thus, PAD2 and 4 but not PAD1, 3, and 6 sustain the viral cell cycle of HCMV. These results were further confirmed in HFFs transfected with siRNA against PAD2 and PAD4, where a protein knockdown efficiency of $\sim 100$ and $70 \%$, respectively (Supplementary Fig. 4d), resulted in an even higher viral reduction of 1 and 2 logs, respectively (Supplementary Fig. 4e). In addition, while siRNA controltransfected HFFs treated with $100 \mu \mathrm{M} \mathrm{Cl-A}$ showed a 1-log reduction in the viral load, no significant differences were observed in PAD2- or PAD4-depleted cells (Supplementary Fig. 4e), indicating no predominant role of one isoform over the other in our working model.

IFN-inducible proteins are the main targets of PAD-mediated citrullination. To identify which proteins (i.e., cellular and/or viral) were deiminated during HCMV infection, we performed citrullinome analysis on HCMV-infected cells harvested at 48 and 96 hpi. Consistent with our earlier findings, we observed a massive increase in overall protein citrullination in HCMV-infected cells at both 48 and 96 hpi compared to uninfected control cells, even though citrullination levels were slightly diminished at 96 hpi compared to 48 hpi (Fig. 4a and Supplementary Data 1, 2, and 3), confirming our previous results (Fig. 1a). In addition to detecting numerous citrullinated viral proteins-35 at $48 \mathrm{hpi}$ and 40 proteins at $96 \mathrm{hpi}$-we noticed an even higher number of 


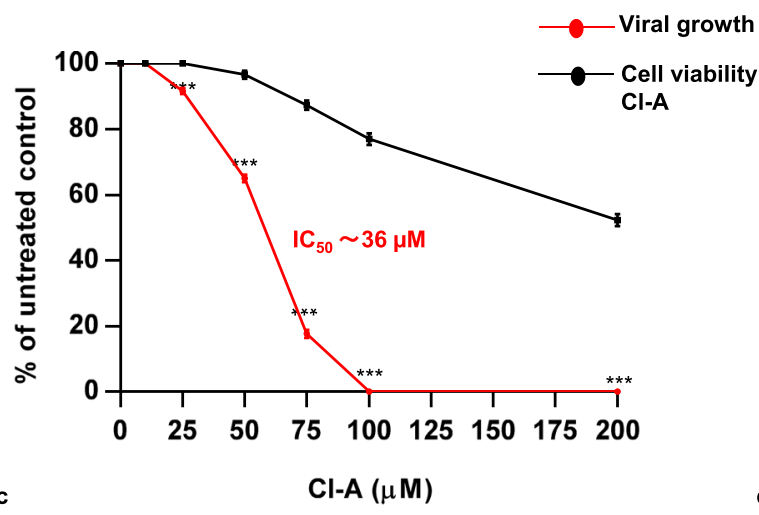

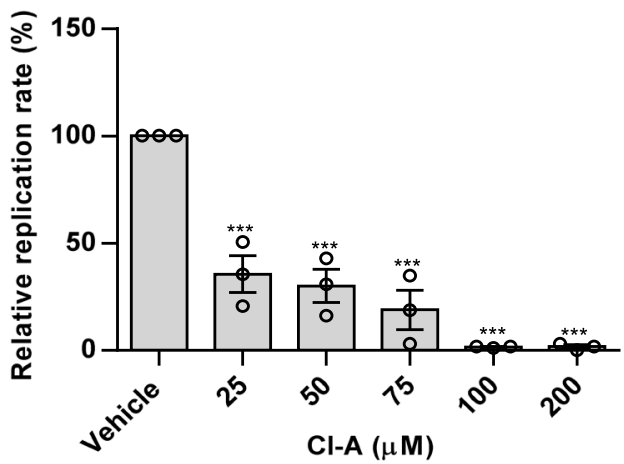

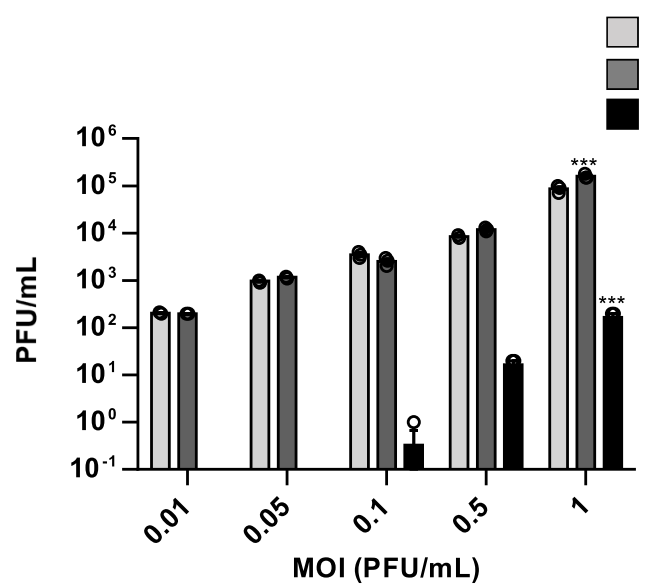

Untreated Vehicle CI-A
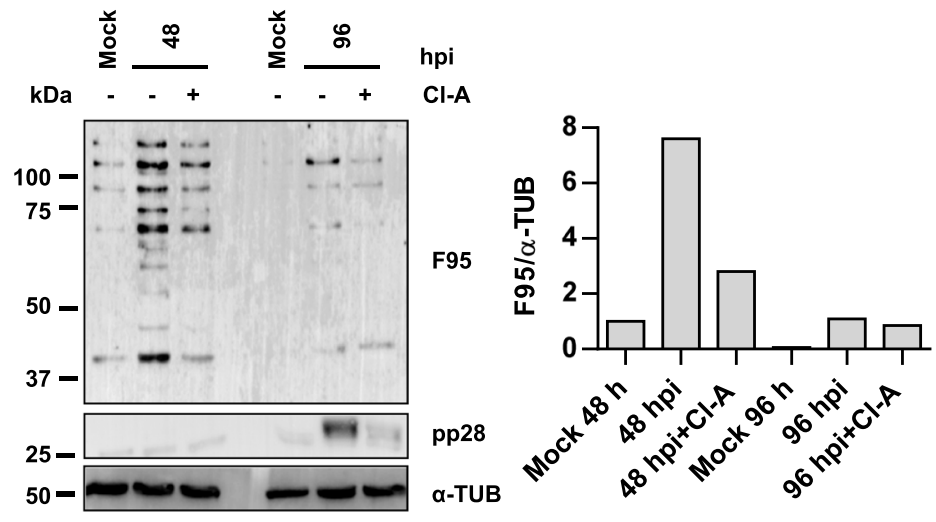

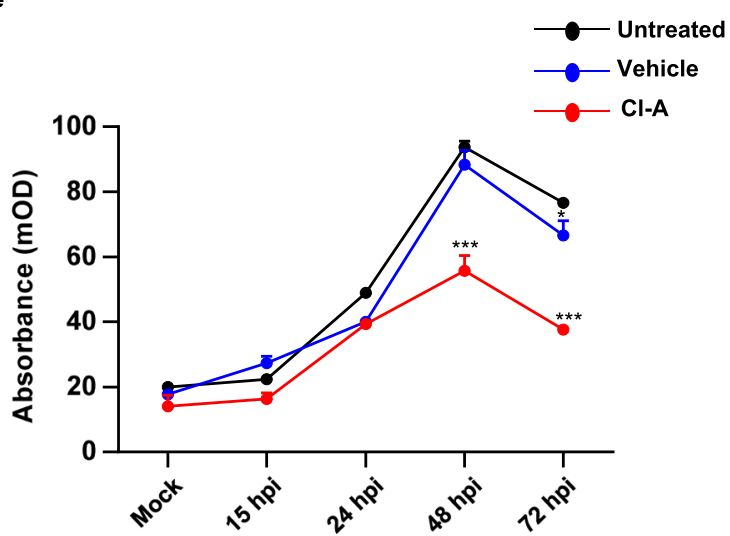

f

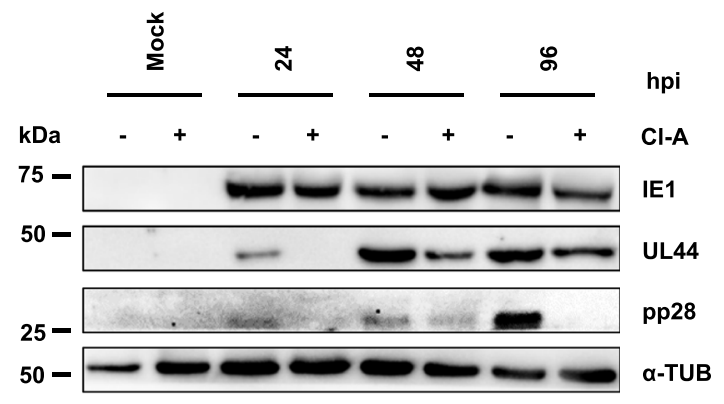

citrullinated host cell proteins-177 at $48 \mathrm{hpi}$ and 122 at $96 \mathrm{hpi}$. Using PANTHER software, we were able to identify a wide range of citrullinated host proteins falling into various functional classes, among which cytoskeletal proteins, chaperones, oxidoreductase, hydrolase, and nucleic acid binding proteins were more frequently found at both time points of infection (Supplementary Fig. 5a). Of particular interest was the significant citrullination at $48 \mathrm{hpi}$ of several members of the interferon (IFN)-induced protein with tetratricopeptide repeat (IFIT) family, such as IFIT1, IFIT2 and IFIT3, and of the IFN-inducible myxovirus resistance 1 (Mx1) gene product (Fig. 4a, left panel) - at $96 \mathrm{hpi}$, citrullination of these proteins was no longer detectable (Fig. 4a, right panel).

To validate these findings, total proteins from mock or infected HFFs at 48 hpi were immunoprecipitated with the anti-citrulline F95 antibody and subjected to immunoblotting using antibodies against Mx1, IFIT1, IEA, UL44, and pp65. As shown in
Supplementary Fig. 5b, all five proteins were robustly deiminated following infection with HCMV.

To corroborate our finding that IE1 is crucial for PAD induction and subsequent citrullination, we performed an additional citrullinome analysis on uninfected HFFs, and wildtype AD169, or mutant AD169 IE1-infected HFFs at $48 \mathrm{hpi}$ (Fig. 4b and Supplementary Data 4 and 5). Consistent with previous results, we detected a significant overall protein citrullination in AD169-infected cells at $48 \mathrm{hpi}$, with IFIT1, IFIT2, and IFIT3, and Mx1 being among the most highly deiminated cellular proteins compared to uninfected control cells (Fig. 4b, left panel). In contrast, upon infection with AD169 $\mathrm{IE} 1$, we observed a 6.3-, 3.5-, and 2.2-fold decrease in IFIT1, Mx1, and IFIT3 enrichment, respectively (Fig. 4b, right panel), which further supports the crucial role played by the IE1 protein in PAD-mediated citrullination during HCMV infection. 
Fig. 2 Cl-A blocks HCMV replication. a HFFs were infected with HCMV (MOI 0.1 PFU/cell) and then treated with increasing concentrations of Cl-A, which were given $1 \mathrm{~h}$ prior to virus adsorption and kept throughout the whole experiment. At $144 \mathrm{hpi}$, viral plaques were microscopically counted and expressed as a percentage relative to untreated controls. The number of plaques is plotted as a function of $\mathrm{Cl}-\mathrm{A}$ concentration. The concentrations resulting in $50 \%$ plaque formation $\left(\mathrm{IC}_{50}\right)$ reduction are represented by the red line. The number of viable cells was determined for each $\mathrm{Cl}-\mathrm{A}$ concentration using the $\mathrm{MTT}$ method (black line). Values are expressed as means \pm SEM (error bars) of three independent experiments (untreated vs. $25 \mu \mathrm{M} \mathrm{Cl-A} P<0.001$, untreated vs. $50 \mu \mathrm{M} \mathrm{Cl-A} P<0.001$, untreated vs. $75 \mu \mathrm{M} \mathrm{Cl-A} P<0.001$, untreated vs. $100 \mu \mathrm{M} \mathrm{Cl-A} P<0.001$, untreated vs. $200 \mu \mathrm{M} \mathrm{Cl-A} P<0.001$, one-way ANOVA followed by Bonferroni's post test). $\mathbf{b}$ To determine the number of viral DNA genomes in HCMV-infected HFFs, viral DNA was isolated at 144 hpi and analyzed by qPCR using primers amplifying a segment of the IE1 gene. GAPDH was used to normalize HCMV genome counts. Values are expressed as mean $\pm \mathrm{SEM}$ of three independent experiments (vehicle vs. $25 \mu \mathrm{M} \mathrm{Cl}-\mathrm{A} P<0.001$, vehicle vs. $50 \mu \mathrm{M} \mathrm{Cl}-\mathrm{A} P<0.001$, vehicle vs. $75 \mu \mathrm{M} \mathrm{Cl-A} P<0.001$, vehicle vs. $100 \mu \mathrm{M} \mathrm{Cl-A} P<0.001$, vehicle vs. $200 \mu \mathrm{M} \mathrm{Cl-A} P<0.001$, one-way ANOVA followed by Bonferroni's post test). c HFFs were infected with $\mathrm{HCMV}$ at increasing MOIs (0.01-1 PFU/cell) and then treated with $100 \mu \mathrm{M} \mathrm{Cl-A}$ or vehicle. Viral supernatants were collected at 144 hpi and analyzed by standard plaque assay. Values are expressed as mean \pm SEM of three independent experiments ( $\mathrm{MOI} 1$ : untreated vs. vehicle $P<0.001$, untreated vs. $\mathrm{Cl}-\mathrm{A}$ $P<0.001$, two-way ANOVA followed by Bonferroni's post test). d Protein lysates from uninfected (mock) or infected HFFs (48 and 96 hpi) with ( + ) or without (-) $100 \mu \mathrm{M} \mathrm{Cl-A}$ were subjected to immunoblotting using the anti-peptidylcitrulline F95 antibody to detect citrullinated proteins, anti-pp28 to assess HCMV infection, or anti- $\alpha$-tubulin ( $\alpha$-TUB) to show equal loading. The densitometric analysis shown is representative of three independent experiments. Densitometry values of F95 are normalized to those of $\alpha$-tubulin. e PAD enzymatic activity assay. Histone H3 was immobilized on a 96 -well microtiter plate and incubated with protein lysates from HCMV-infected HFFs or uninfected (mock) at the indicated time points, in the presence (red line) or absence (untreated or vehicle alone, black and blue line, respectively) of $\mathrm{Cl}-\mathrm{A}$. The conversion of peptidylarginine to peptidylcitrulline was detected with an anti-H3 citrulline antibody. Detection of the bound antibodies was performed by ELISA. Values are expressed as means \pm SEM (error bars) of three independent experiments (48 hpi: untreated vs. Cl-amidine $\mathrm{P}<0.001,72$ hpi: untreated vs. $\mathrm{Cl}-\mathrm{A} P<0.001,72$ hpi: untreated vs. vehicle $P<0.05$, two-way ANOVA followed by Bonferroni's post tests). f Protein lysates from uninfected (mock) or infected HFFs (24, 48, or $72 \mathrm{hpi})$ at an MOI of $1 \mathrm{PFU} / \mathrm{cell}$ treated with or without $\mathrm{Cl}-\mathrm{A}(+)$ or vehicle $(-)$ were analyzed by immunoblotting for viral expression (IE1-72 kDa, UL44, and pp28) and normalized to $\alpha$-tubulin $\left(\alpha\right.$-TUB). One representative blot of three independent experiments is shown. Data are shown as the mean \pm SEM, ${ }^{\star} P<0.05,{ }^{\star \star} P<0.01,{ }^{\star \star \star} P<0.001$.

The IFN-inducible proteins IFIT1 and Mx1 exert antiviral activity against HCMV. IFITs are a family of antiviral RNAbinding proteins highly expressed during antiviral immune responses. In this regard, IFIT family members, known primarily for their antiviral activity against RNA viruses, have only recently been implicated in the innate immune response against DNA viruses $^{28}$. Specifically, $\mathrm{Li}$ and Swaminathan ${ }^{29}$ have shown that human IFIT1, IFIT2, and IFIT3 proteins can suppress lytic replication of the Kaposi's sarcoma-associated herpesvirus (KSHV). Furthermore, Zhang et al. demonstrated that IFIT1 overexpression significantly impairs HCMV replication in astrocytes, whereas IFIT1 knockdown sustains the viral cycle of $\mathrm{HCMV}^{30}$.

The other IFN-inducible target of HCMV-induced deimination, $\mathrm{Mxl}$, is a member of the dynamin-like large GTPase family involved in protection against negative-stranded RNA virus infection and several DNA viruses ${ }^{31}$. Interestingly, MX2 has been recently shown to display antiviral activity against herpesviruses ${ }^{32,33}$.

To gain further insight into the role of these genes during HCMV infection, we measured virus production in HCMVinfected HFFs after siRNA-mediated depletion of Mx1 or IFIT1the latter having been shown to exert antiviral activity against HCMV only in fetal astrocytes upon lentiviral overexpression ${ }^{30}$. Following transfection with specific siRNAs against IFIT1 or Mx1 (siIFIT1, siMx1) and subsequent infection with HCMV for $48 \mathrm{~h}$, we achieved a $\sim 60 \%$ reduction in IFIT1 protein expression and near to complete silencing of Mxl protein (Supplementary Fig. 6a). Importantly, in both cases, gene silencing resulted in 1$\log$ higher levels of virus production compared to siCTRLtransfected cells (Fig. 5a).

Given the emerging evidence supporting an antiviral role of IFIT1 against HCMV infection, we asked whether ectopic expression of IFIT1 would curb viral spread in our system. To test this hypothesis, HFFs were transduced with AdVIFIT1 or $\mathrm{LacZ}$ as a control at an MOI of 10 and, $24 \mathrm{~h}$ post transduction (hpt), infected with HCMV at an MOI of 1 for $144 \mathrm{~h}$. As expected, overexpression of IFIT1 (Supplementary Fig. 6b) reduced viral titer by >2-log compared to AdVLacZ control (Fig. 5b), indicating that IFIT1 strongly impairs HCMV infection in HFFs.
In vitro citrullination of IFIT1 inhibits its binding to triphosphorylated RNA. In order to elucidate the effect of citrullination on IFIT1, we exploited its well-established ability to preferentially bind viral RNA harboring a triphosphate group at its C-terminus ( $5^{\prime}$-ppp-RNA $)^{34}$, which has been shown to be detrimental for the growth of some RNA viruses containing 5'-ppp-RNA. Interestingly, the arginine at position 187 in a highly charged carboxyterminal groove appears necessary for IFIT1 binding ${ }^{35}$. In this context, we first attempted to determine whether this arginine 187 could be citrullinated by PAD2 after assessment of its in vitro citrullination using the Rh-PG (Supplementary Fig. 6c). LC-MS/ MS peptide analysis of recombinant IFIT1 mock or treated with PAD2 for $3 \mathrm{~h}$ identified several arginine positions citrullinated in vitro by PAD2, including arginine 187 (Supplementary Data 6). We then conducted a gel shift assay to assess the ability of IFIT1 to bind to 5'-ppp-RNA according to its citrullination state. In vitro transcribed 5'-ppp-RNA was incubated with recombinant IFIT1, either mock or treated with $\mathrm{PAD} 2$, and then loaded on an agarose gel. As expected, mock IFIT1 induced a delay in 5'-ppp-RNA migration in comparison with control RNA, indicating the formation of an IFIT1-RNA complex. This effect was reduced when IFIT1 was previously treated with PAD2 for $3 \mathrm{~h}$ (Fig. 5c).

In vitro citrullination of UL44 affects long-chain DNA synthesis. To determine whether citrullination could also affect viral protein activity, we measured the ability of native vs. citrullinated forms of VPAP, also known as ICP36 or UL44, to cooperate with the viral DNA polymerase UL54 in promoting long-chain DNA synthesis ${ }^{36,37}$, using poly (dA)-oligo (dT) $)_{12-18}$ as primer template (Fig. 5d, and Supplementary Fig. 6d). The choice of VPAP was due to its high deimination rate observed at both 48 and $96 \mathrm{hpi}$ compared to mock control (Fig. 4a, and Supplementary Data 1 and 3). To perform this assay, we employed a truncated form of UL44 (UL44AC290) retaining all known biochemical activities of full-length UL44 for DNA polymerase stimulation of full-length UL44 ${ }^{38}$. As expected, in the presence of UL54 alone we could not detect long-chain DNA, whereas long-chain DNA synthesis was readily detected when both UL54 and UL44 $\triangle$ C290 were added to the reaction (Fig. 5d and Supplementary 6d). Notably, PAD2- or PAD4-mediated citrullination of UL44 $\triangle \mathrm{C} 290$ reduced the 

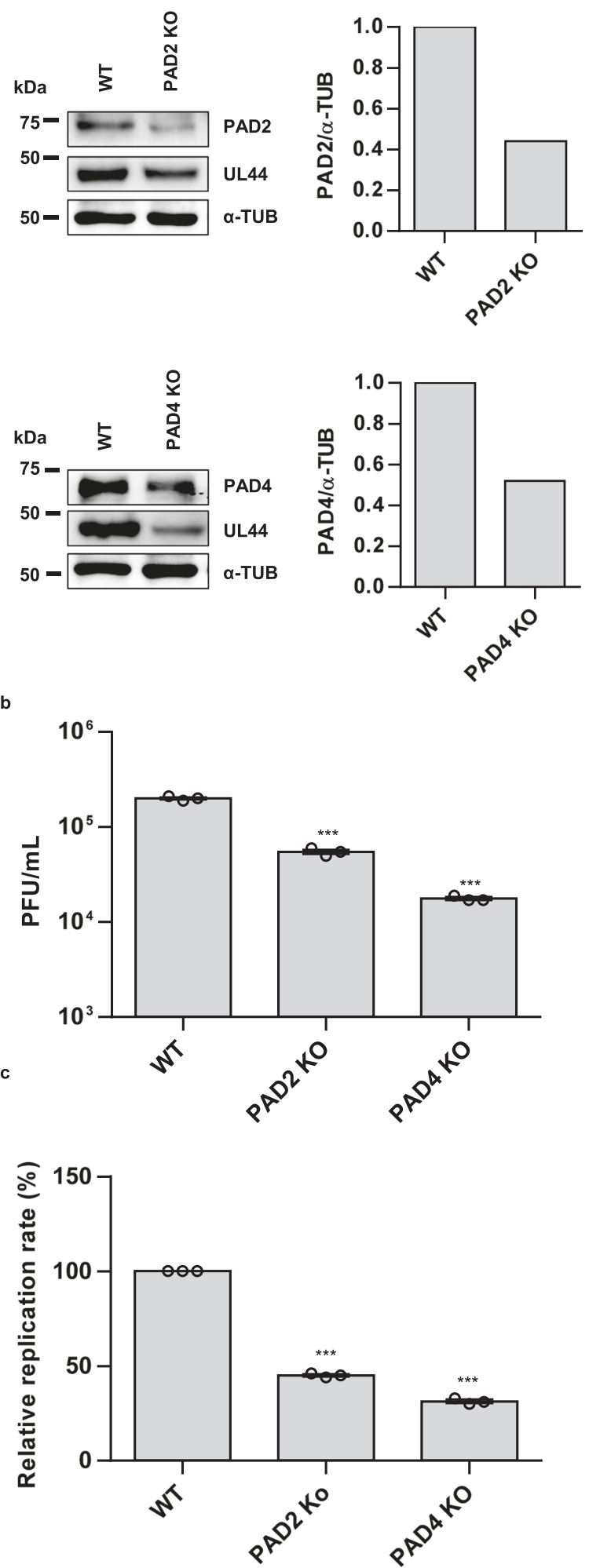

synthesis of long-chain DNA substantially (Fig. 5d and Supplementary Fig. 6d). This inhibition was not due to carryover of $\mathrm{PAD} 2$ or PAD4 because addition of PAD2 and 4 to the reaction did not inhibit DNA synthesis (Fig. 5d and Supplementary 6d). Finally, in vitro citrullination of UL $44 \Delta$ C 290 was confirmed by reduced mobility on SDS-PAGE compared to untreated or mocktreated controls (Supplementary Fig. 6e), as shown previously for other citrullinated proteins ${ }^{39}$.
Fig. 3 Effect of PAD2 and PAD4 gene knockout on HCMV replication. a Knockout (KO) gene variants in HFFs for PAD2 (PAD2 KO) and PAD4 (PAD4 KO) were generated using CRISPR/Cas9 technology. The efficiency of PAD2 and PAD4 protein depletion at $48 \mathrm{hpi}$ was assessed by immunoblotting using antibodies against PAD2, PAD4, or $\alpha$-tubulin ( $\alpha$ TUB), for equal loading. An anti-UL44 antibody was used to verify HCMV infection. The western blot and relative densitometric analysis are representative of three independent experiments. Values are expressed as fold change in PAD2 and 4 expression normalized to $\alpha$-tubulin ( $\alpha$-TUB). b HFFs KO cells were infected with $\mathrm{HCMV}$ at an MOI of $0.1 \mathrm{PFU} /$ cell. Viral supernatants were collected at the indicated time points and analyzed by standard plaque assay. Values are expressed as means \pm SEM of three independent experiments (WT vs. PAD2 KO $P<0.001$, WT vs. PAD4 KO $P<0.001$, one-way ANOVA followed by Bonferroni's post test). c To determine the number of viral DNA genomes in HCMV-infected HFFs KO cells (MOI 0.1), viral DNA was isolated at $144 \mathrm{hpi}$ and analyzed by qPCR with primers amplifying a segment of the IE1 gene. GAPDH was used to normalize HCMV genome counts. Values are expressed as mean \pm SEM of three independent experiments (WT vs. PAD2 KO $P<0.001$, WT vs. PAD4 KO $P<0.001$, one-way ANOVA followed by Bonferroni's post test). Data are shown as the mean \pm SEM, ${ }^{\star} P<0.05,{ }^{\star \star} P<0.01,{ }^{\star \star \star} P<0.001$.

\section{Discussion}

Citrullination is an irreversible PTM catalyzed by PADs enzymes. This modification results in the conversion of an arginine side chain into citrulline, with loss of one positive charge and consequent reduction in protein net charge. This PTM can in turn increase protein hydrophobicity and alter intra- and intermolecular interactions, affecting protein conformation, stability, and binding of a wide range of proteins involved in numerous physiological processes, such as apoptosis, differentiation, and gene regulation ${ }^{10}$. Eventually, these structural changes can lead to the gain or loss of protein functions ${ }^{40}$. In this study, we have uncovered the role of citrullination in promoting viral persistence through the deimination of cellular proteins endowed with antiviral activity. Among these, we have focused our attention on IFIT1 and Mx1, two IFN-stimulated genes (ISGs) with a wellestablished inhibitory activity against various DNA and RNA viruses $^{28-33}$. We show that silencing of either gene results in augmented virus production, whereas ectopic expression of IFIT1 inhibits viral growth, in good agreement with previous results obtained using KSHV-infected cells ${ }^{29}$. Finally, we report that PAD-mediated in vitro deimination of IFIT1 severely affects its ability to bind to 5'-triphosphorylated RNA, thereby impairing the antiviral activity of this protein.

Taken together, our findings suggest that HCMV can trigger PAD-mediated deimination of arginine residues of cellular proteins in order to enhance viral growth, a possibility supported by previous work showing that the arginine at position 187 of the IFIT1 protein is necessary for its binding to 5'-triphosphorylated $\mathrm{RNA}^{34}$. This residue is located within a highly charged carboxyterminal groove that allows recognition and sequestration of viral nucleic acids. Thus, in future studies it will be crucial to characterize the yet unknown mechanisms of IFIT1- and Mx1mediated inhibition of HCMV growth and to ascertain whether citrullination can hijack these defense pathways in vivo.

Noteworthy, we demonstrate that HCMV IE1 protein is a pivotal factor for PAD induction and subsequent protein citrullination. In this regard, our citrullinome analysis reveals that a variety of cellular proteins, such as IFITs or Mx1, are significantly less citrullinated upon infection with the AD1690IE1 mutant compared to the wild-type virus, implying a central role of IE1 in mediating HCMV-induced citrullination events. The residual amount of citrullinated-IFN-inducible-proteins still detectable 
a

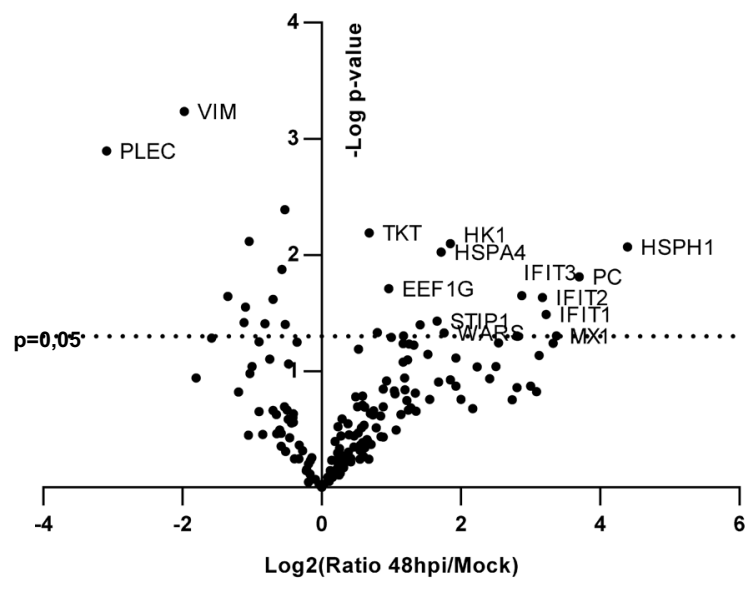

Viral Citrullinome 48 hpi

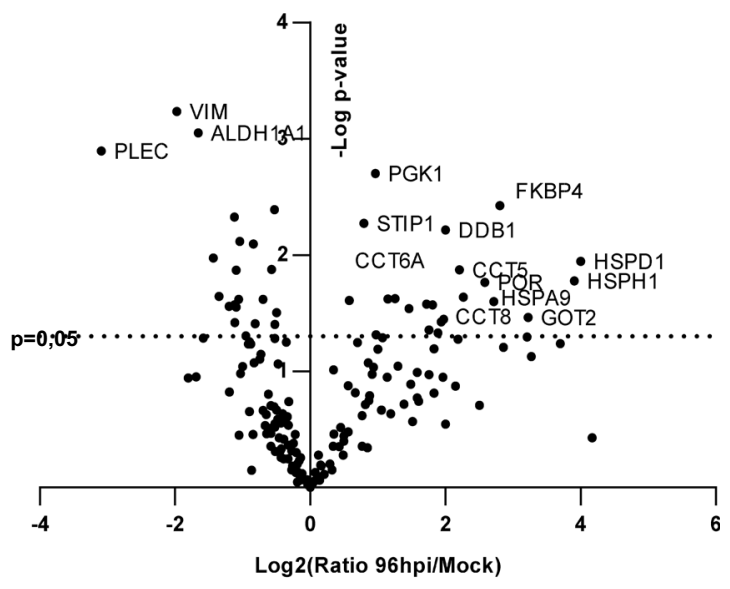

Viral Citrullinome 96 hpi

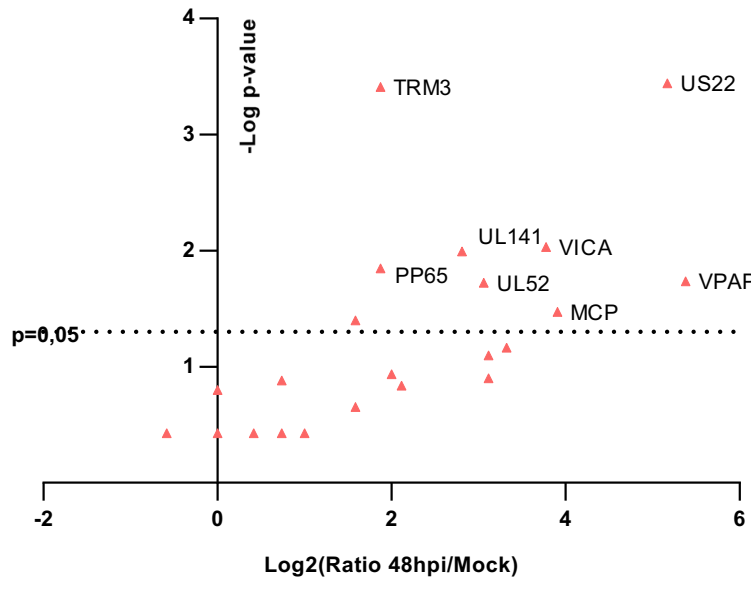

Log2(Ratio 48hpi/Mock)

b

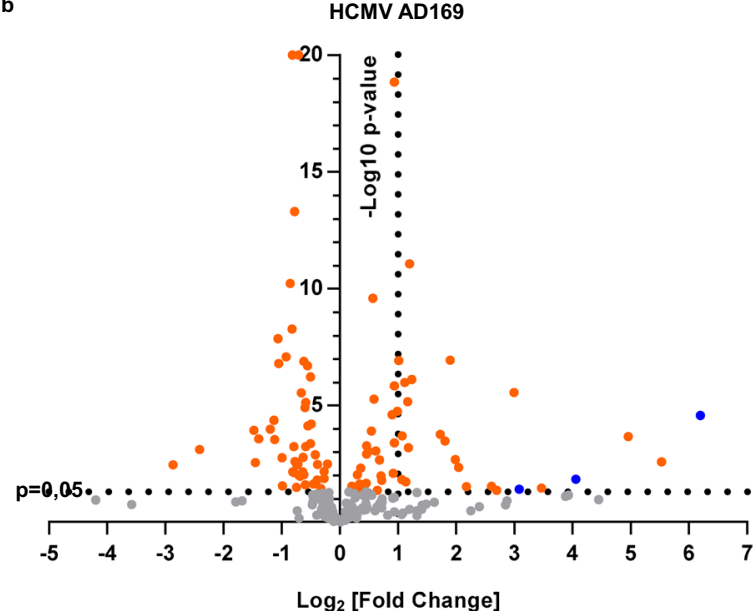

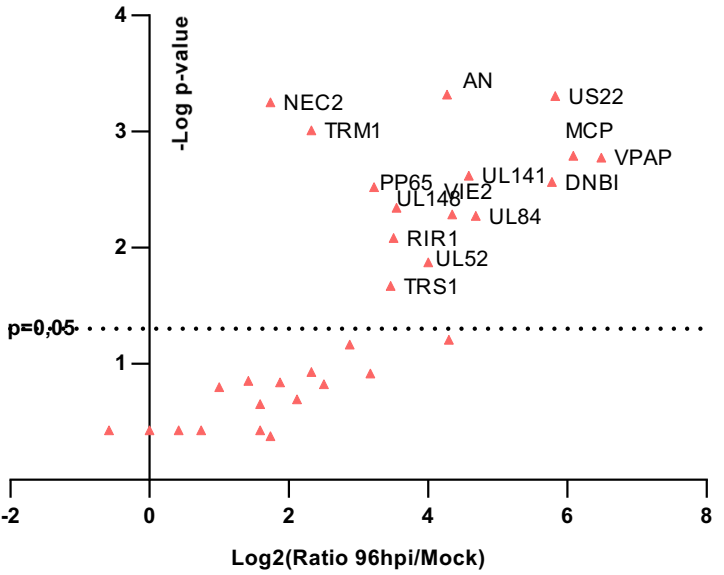

HCMV AD169DIE1

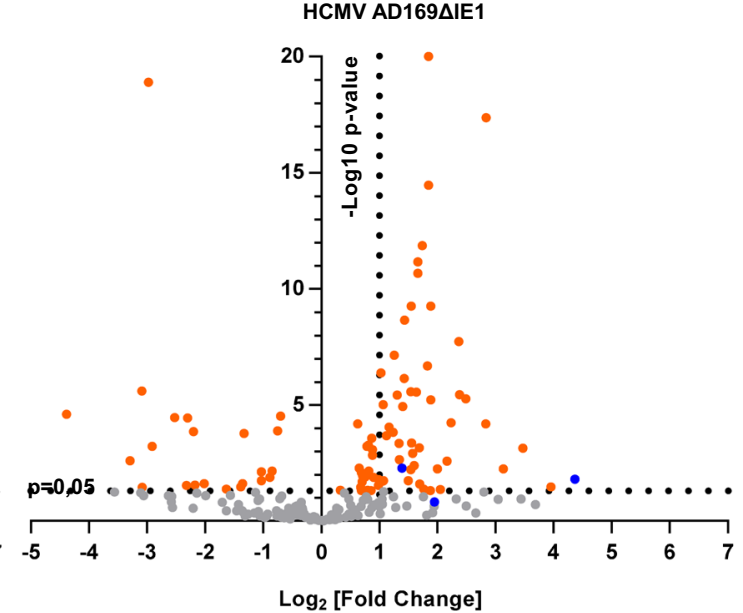

Fig. 4 Characterization of the citrullinated proteome (citrullinome) of HCMV-infected cells. a Volcano plot depicting the host (upper panel-circle) and viral (lower panel-triangle) citrullinated proteins of infected cells vs. mock-infected cells at 48 hpi (left panel) and 96 hpi (right panel). Cell lysates from uninfected (mock) or HCMV-infected HFFs (MOI 1) were exposed to a biotin-PG to isolate citrullinated proteins on streptavidin agarose. Bound proteins were then subjected to on-bead tryptic digestion and analyzed by LC-MS/MS-in the graph, every identified citrullinated protein corresponds to a dot. The $x$ axis represents the ratio of citrullination between mock and infected cells at the indicated time points, while the $y$ axis indicates the statistical significance. Both variables were plotted on a logarithmic scale $(n=3)$. b Volcano plot depicting the host citrullinated proteins in HCMV AD169- (left panel) and AD1694IE1- (right panel) vs. mock-infected HFFs at 48 hpi. Cell lysates from uninfected (mock) or HCMV-infected (MOI 1) HFFs were exposed to a biotinPG to isolate citrullinated proteins on streptavidin agarose. Bound proteins were then subjected to on-bead tryptic digestion and analyzed by LC-MS/MSin the graph, every identified citrullinated protein corresponds to a dot. The $x$ axis represents the ratio of citrullination between mock and infected cells at the indicated time points, while the $y$ axis indicates the statistical significance. Both variables were plotted on a logarithmic scale $(n=3)$. 
a

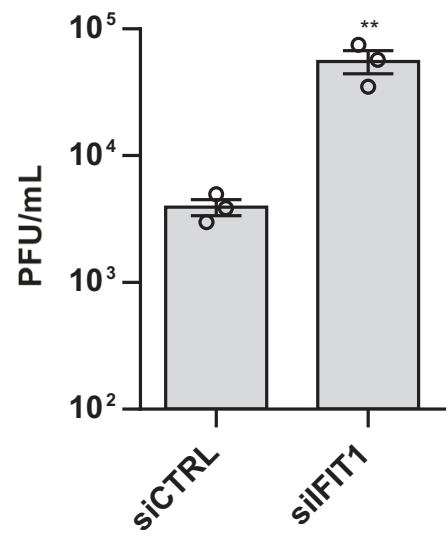

c

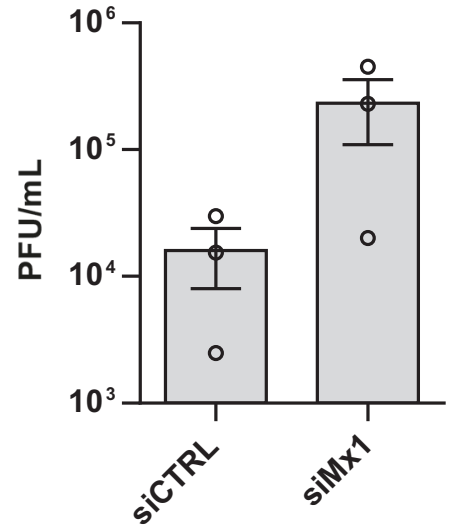

b

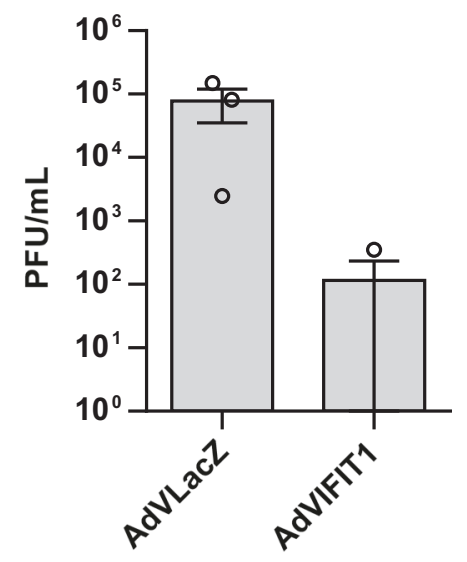

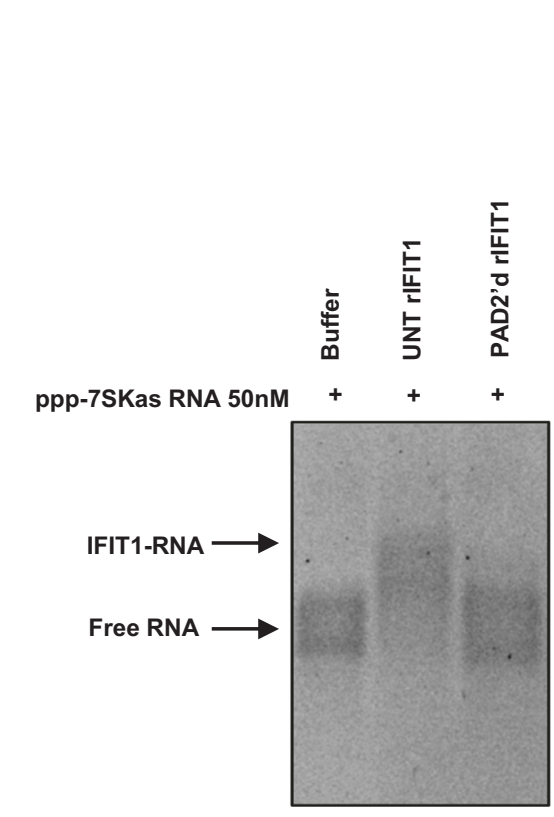

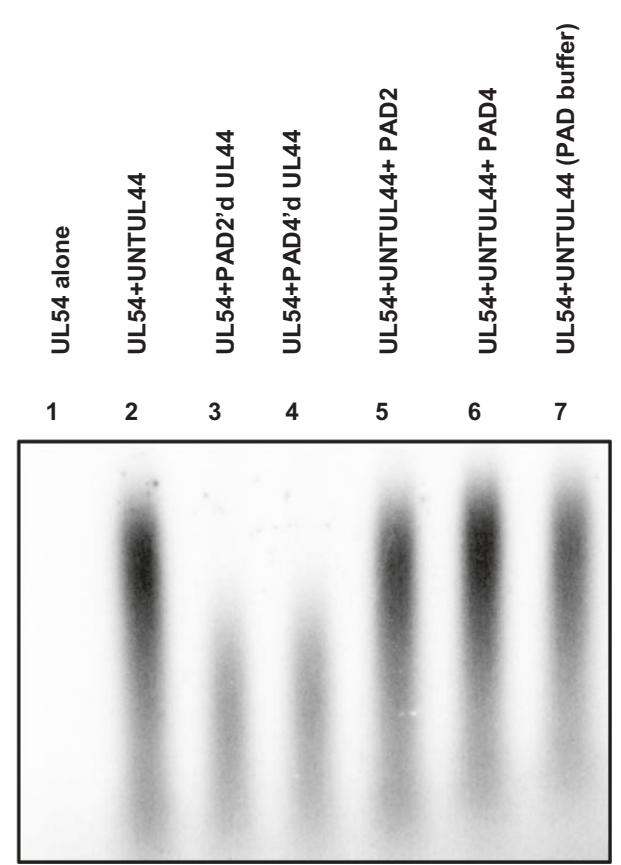

Fig. 5 The antiviral role of IFIT1 and Mx1 against HCMV. a HFFs were silenced for IFIT1 and Mx1 using specific siRNAs (silFIT1, siMx1, respectively). As negative control cells were also similarly transfected with scrambled siRNA (siCTRL). At $24 \mathrm{hpt}$, cells were infected with $\mathrm{HCMV}$ at an MOI of $0.1 \mathrm{PFU} / \mathrm{cell}$. Viral supernatants were collected at $144 \mathrm{hpi}$ and analyzed by standard plaque assay. Values are expressed as means \pm SEM of three independent experiments (siCTRL vs. silFIT1 $P=0.0111$, unpaired two-tailed $t$ test; siCTRL vs. siMx1 $P>0.05$, unpaired two-tailed $t$ test). b HFFs were transduced with AdVIFIT1 or AdVLacZ at an MOI of $10 \mathrm{PFU} /$ cell. Subsequently, cells were infected with HCMV at an MOI of 1. The extent of virus replication was measured at 144 hpi. Results are expressed as means \pm SEM of three independent experiments (AdVLacZ vs. AdVIFIT1 P $>0.05$, unpaired two-tailed $t$ test). c Gel electrophoretic mobility shift assay of IFIT1 binding to PPP-7SKas RNA. 50 nM of in vitro transcribed 7SK 5'-ppp-RNA was incubated with only buffer (buffer), $5 \mu \mathrm{M}$ of recombinant IFIT1, either untreated (UNT rIFIT1) or treated with PAD2 (PAD2'd rIFIT1) and loaded on a tris-glycine agarose gel. Data are representative of three experiments. $\mathbf{d}$ Long-chain DNA synthesis directed by UL54 in the presence or absence of purified UL44DC290 was assayed by measuring the incorporation of labeled $\left.{ }_{32} \mathrm{P}\right] \mathrm{TTP}$ with a poly $(\mathrm{dA})$-oligo(dT) primer template. DNA products were resolved on an alkaline agarose gel that was exposed to film and, for quantification, to a phosphorescence screen followed by scanning with a Typhoon scanner. The image shows products directed by UL54 alone, lane 1), or by UL54 in the presence of untreated (UNT) UL44 $C 290$ (lane 2), in the presence of UL44 or PAD4 (PAD2'd, PAD4'd; lanes 3 and 4, respectively), in the presence of UNT UL44AC290 but with 270 pM PAD2 (lane 5) or 370 pM PAD4 (lane 6) added to the DNA synthesis reaction, or in the presence of UL44 incubated in PAD reaction buffer, but without PADs (mock-PAD, lane 7). One representative gel of three independent experiments is shown. Data are shown as the mean $\pm \mathrm{SEM},{ }^{\star} P<0.05,{ }^{\star \star} P<0.01,{ }^{\star \star \star} P<0.001$.

upon infection with AD169 $\triangle \mathrm{IE} 1$ suggests that other (viral) proteins may be implicated in PAD induction or that a small number of inactive PADs may be present inside the cell and still capable of citrullinating certain targets upon HCMV-mediated activation. Our findings are consistent with a recent study by Casanova et al. showing that HRV infection upregulates PAD activity and that citrullination of the human cathelicidin LL-37 suppresses its antiviral activity against HRV infection, corroborating the role of citrullination as a viral evasion mechanism employed by certain viruses. Noteworthy, citrullination of this host defense peptide has been shown to disrupt its antimicrobial role, both against bacterial and viral infections, including HRV, and increase its susceptibility to degradation ${ }^{41-46}$.

Another important observation of our study is that, upon cellular entry, several viral proteins are citrullinated as well, raising the hypothesis that citrullination may concomitantly 
influence the activity of both viral and cellular proteins. Among viral proteins, we find that in vitro citrullination of UL44, an accessory protein that increases the DNA processivity of UL54 $4^{36,37}$, reduces its ability to drive long-chain DNA synthesis. Although the physiological role of UL44 citrullination during HCMV infection cannot be inferred from the results of this study, it is tempting to speculate that HCMV may exploit UL44 citrullination to fine-tune its DNA replication during specific phases of viral infection.

Overall, our observation that HCMV growth relies, in part, on PAD-mediated citrullination suggests the attractive prospect that deimination of host-and possibly-viral proteins may be exploited for the design of antiviral agents against HCMV and, more in general, herpesviruses. An alternative pharmacological strategy_-perhaps less costly and time-consuming-could rely on repurposing existing $\mathrm{PAD}$ inhibitors, such as $\mathrm{Cl}-\mathrm{A}$, which we have shown to have a potent inhibitory effect against HCMVinduced citrullination and viral growth.

As HCMV has been implicated in various autoimmune, inflammatory, and cardiovascular diseases as well as cancer development, all characterized by a high degree of protein citrullination, it is possible that HCMV-mediated protein citrullination also constitutes a key event in the pathogenesis of such diseases.

\section{Methods}

Cells and viruses. Human foreskin fibroblasts (HFFs, ATCC SCRC-1041 ${ }^{\mathrm{Tu}}$ ), African green monkey kidney cells (Vero; Sigma-Aldrich 84113001), human HEK 293 from the human kidney (embryonic) (HEK 293, Sigma-Aldrich 85120602), HEK 293T (HEK 293T, ATCC ${ }^{\circledast}$ CRL-3216 ${ }^{\text {ma }}$ ) were cultured in Dulbecco's modified Eagle's medium (DMEM) supplemented with $10 \%$ fetal calf serum (FCS) (SigmaAldrich, Milan, Italy). CD4 + lymphoblastoid T (C8166, ECACC 88051601) were kept in RPMI 1640 (GIBCO, Grand Island, NY) supplemented with 10\% FCS (Sigma-Aldrich, Milan, Italy).

HCMV strain Merlin, kindly provided by Gerhard Jahn and Klaus Hamprecht (University Hospital of Tübingen, Germany), and the HCMV laboratory strain AD169 (ATCC-VR538), were propagated and titrated on HFFs ${ }^{47}$. AD169 $\Delta$ IE1 was kindly provided by Thomas Stamminger (University of Ulm, Germany). UVinactivated Merlin was prepared using a double pulse of UV-B light $\left(1.2 \mathrm{~J} / \mathrm{cm}^{2}\right)$.

A clinical isolate of adenovirus was propagated in HEK 293 cells, whereas clinical isolates of HSV -1 and HSV-2 were grown in Vero cells and titrated by standard plaque assay ${ }^{48}$. HIV-1 $1_{\text {IIIb }}$ strain stock was prepared in C8166 cells, as previously described ${ }^{49}$

Recombinant adenoviral vectors (AdV) encoding HCMV IE2 (AdVIE2) and Escherichia coli $\beta$-galactosidase (AdVLacZ) have been previously described ${ }^{47,50}$, while AdV-IE72 (AdVIE1) was provided by Dr. Timothy F. Kowalik (University of Massachusetts Medical School, Worcester, MA) ${ }^{51}$. Recombinant AdV stocks were propagated and titrated in HEK 293 by standard plaque assay ${ }^{47,50,51}$.

Reagents and proteins. Recombinant human PAD2, PAD4, and Cl-A were from Cayman Chemical (Ann Arbor, USA). Cycloheximide and Foscarnet were from Sigma-Aldrich (Milan, Italy). BB-Cl-A was kindly provided by P. R. Thompson (University of Massachusetts, Medical School).

The plasmid pET30A hIFIT1-GST-His was kindly provided by A. Pichlmair (Technische Universitaet Munich, Germany). pSGIE72 IE1-encoding plasmid was used in the quantitative nucleic acid analysis. The pSicoR-CRISPR-Cas9 vector (RP-557) was kindly provided by R. J. Lebbink (UMC, Utrecht).

In vitro antiviral assay. HFFs, HEK 293 , and Vero were incubated with increasing concentrations of Cl-A $(0,25,50,75,100$, or $200 \mu \mathrm{M}) 1 \mathrm{~h}$ prior to being infected with HCMV, adenovirus or HSV-1 or HSV-2 at an MOI of 0.1 . Following virus adsorption $\left(2 \mathrm{~h}\right.$ at $\left.37^{\circ} \mathrm{C}\right)$, cultures were maintained in medium containing the corresponding $\mathrm{Cl}-\mathrm{A}$ and then incubated until control cultures displayed extensive cytopathology ( 7 days pi for HCMV, 6 days pi for adenovirus, and 48 hpi for HSV-1 and HSV-2). Thereafter, the cells and supernatants from the antiviral assay were harvested and disrupted by sonication. The extent of virus replication was then assessed by titrating the infectivity of supernatants by standard plaque assay on HFFs for HCMV, on HEK 293 for adenovirus, and on Vero cells for HSV-1/HSV-2 4 ,48.

Cell viability assay. To determine cell viability, HFFs, HEK 293, and Vero were exposed to increasing concentrations of Cl-A. After 6 days of incubation, the number of viable cells was determined by the 3-(4,5-dimethylthiazol-2-yl)-2,5diphenyltetrazolium bromide (MTT) method ${ }^{52}$. Briefly, MTT solutions from the
Stock (final concentration $500 \mu \mathrm{g} / \mathrm{ml}$ ) were added, and cells were incubated in a $\mathrm{CO}_{2}$ incubator in the dark for $2 \mathrm{~h}$. Then, the medium was removed and the resulting formazan crystals were dissolved using $100 \mu \mathrm{l}$ of DMSO. Finally, the resulting colored solution was transferred in a 96-well plate, and the absorbance was read at $570 \mathrm{~nm}$ using $630 \mathrm{~nm}$ as reference wavelength on a Victor X3 Multilabel Plate Reader (Perkin Elmer, Waltham, MA, USA; wallac 1420 work station software). The viability of the C8166 cells in presence of scalar concentrations of $\mathrm{Cl}-\mathrm{A}$ was determined by the trypan blue exclusion technique at day 7 pi.

HIV-1 infection and antiviral assay. HIV $-1_{\text {IIIb }}(5 \mathrm{ng} / \mathrm{ml}$ of HIV-1 gag p24) was pre-incubated for $1 \mathrm{~h}$ at $37^{\circ} \mathrm{C}$ with the increasing amount of $\mathrm{Cl}-\mathrm{A}(0,10,25,75$ 100 , or $200 \mu \mathrm{M})$ and then added to C8166 cells $\left(0.5 \times 10^{6}\right.$ cells $\left./ \mathrm{ml}\right)$ for $2 \mathrm{~h}$ at $37^{\circ} \mathrm{C}$ After three washes in $1 \mathrm{X}$ phosphate-buffered saline (PBS), cells were seeded at $5 \times$ $10^{5}$ cells $/ \mathrm{ml}$ into a fresh medium plus the same drug concentration used in the preincubation. The HIV-1 gag p24 amount was determined at day 7 pi in the culture supernatants with the HIV-1 p24 antigen ELISA kit (Biomerieux, Marcy-l'Étoile, France). Mock-infected C8166 cells were used as a negative control. In parallel,

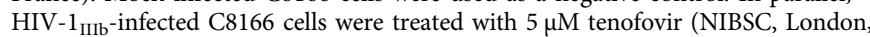
$\mathrm{UK})$ with the same procedure used for the drug treatment.

RNA isolation and quantitative nucleic acid analysis. Total RNA was extracted using the NucleoSpin RNA kit (Macherey-Nagel, Düren, Germany), and $1 \mu \mathrm{g}$ was retrotranscribed using the Revert-Aid H-Minus FirstStrand cDNA Synthesis Kit (Thermo Fisher Scientific, Waltham, USA), according to the manufacturer's instructions. Comparison of mRNA expression between samples (i.e., infected vs. untreated) was performed by SYBR green-based RT-qPCR using Mx3000P apparatus (Stratagene, San Diego, USA), using the primers reported in Supplementary Table 1. To determine the number of viral DNA genomes per nanogram of cellular reference DNA (GAPDH gene), viral DNA levels were measured by quantitative qPCR on an Mx3000P apparatus (Stratagene, San Diego, USA). HCMV DNA copy numbers were normalized by dividing by the amount of human GAPDH gene amplified per reaction mixture. A standard curve of serially diluted genomic DNA mixed with an IE1-encoding plasmid (from $10^{7}$ to 1 copy) was created in parallel with each analysis.

Western blot analysis. Whole-cell protein extracts were prepared and subjected to immunoblotting ${ }^{53}$. Briefly, equal amounts of cell extracts were fractionated by electrophoresis on SDS-polyacrylamide gels and transferred to Immobilon-P membranes (Merck Millipore, Burlington, MA, USA). After blocking with TBS (Tris-buffered saline containing $0.05 \%$ Tween 20 ) containing $5 \%$ milk, membranes were incubated overnight at $4{ }^{\circ} \mathrm{C}$ with the appropriate primary antibodies. In this study, the primary antibodies used were: anti-peptidyl-citrulline, clone F95 (1:500), anti-IFIT1 (1:500), anti-V5 (1:1000), anti-pp65 (1:1000), anti-pp28 (1:1000), antiUL44 (1:1000), anti-Mx1 (1:500), anti-IEA (1:1000), anti-PAD2 (1:1500), antiPAD6 (1:500), anti-PAD4 (1:500), anti-PAD3 (1:500), anti-PAD1 (1:500), antiactin clone C4 (1:1000), and anti- $\alpha$-tubulin (1:1000). The primary antibodies used are detailed in Supplementary Table 2. Membranes were then washed and incubated for $1 \mathrm{~h}$ at room temperature with secondary antibodies: anti-rabbit/mouse IgG and anti-mouse IgM, horseradish peroxidase-linked species-specific whole antibody (Amersham, Merck Life Science S.r.l., Milan, Italy) or goat anti-mouse IgM antibody (Merck Life Science S.r.l., Milan, Italy) (1:2000). Proteins were visualized using ChemiDoc MP Imaging System (Bio-Rad Laboratories Srl), and an enhanced chemiluminescence detection kit (Thermo Fisher Scientific, Waltham, MA, Stati USA). Scanning densitometry of the bands was performed using Image Lab (version 4.6.9; Bio-Rad Laboratories S.r.l., Segrate, Italy).

\section{Detection of citrullination with rhodamine-phenylglyoxal (Rh-PG). Equal} amounts of protein were diluted with $80 \%$ trichloroacetic acid and incubated with $\mathrm{Rh}-\mathrm{PG}$ (final concentration $0.1 \mathrm{mM}$ ) for $30 \mathrm{~min}^{25}$. The reaction was quenched with $100 \mathrm{mM}$ L-citrulline, then centrifuged at $21,100 \times \mathrm{g}$ for $10 \mathrm{~min}$ and washed with ice-cold acetone, and resuspended in $2 \times$ SDS loading dye for gel electrophoresis. Gels were imaged $($ excitation $=532 \mathrm{~nm}$, emission $=580 \mathrm{~nm})$ using a ChemiDoc MP Imaging System (Bio-Rad Laboratories Srl), stained with brilliant blue Gcolloidal solution (Sigma-Aldrich, Milan, Italy).

Enzyme-linked immunosorbent assay activity. Plates (Nunc ${ }^{\circledR} 96$ MaxiSorp $^{\mathrm{m}}$, Sigma-Aldrich, Milan, Italy) were coated with $4 \mu \mathrm{g} / \mathrm{mL}$ of calf thymus histone 3 (Sigma-Aldrich, Milan, Italy) in coating buffer $\left(100 \mathrm{mM} \mathrm{Na} \mathrm{CO}_{3}, 100 \mathrm{mM}\right.$ $\mathrm{NaHCO}_{3}, \mathrm{pH}$ 9.6) and incubated at $4{ }^{\circ} \mathrm{C}$ overnight. Subsequently, they were washed with $1 \times$ TBST (Tris-buffered saline, $0.05 \%$ Tween 20 ). Then, $50 \mu \mathrm{g}$ of protein lysates from mock- or HCMV-infected HFFs at different time points, in the presence or absence of $100 \mu \mathrm{M} \mathrm{Cl}-\mathrm{A}$ or with the same volume of the vehicle as a negative control, were diluted in calcium-free PAD reaction buffer ( $2 \mathrm{mM}$ DTT, $50 \mathrm{mM} \mathrm{NaCl}, 100 \mathrm{mM}$ Tris, $\mathrm{pH}$ 7.57). As a positive control, increasing concentrations of 2.5, 5, and $10 \mathrm{mU}$ of recombinant PAD2 (Cayman Chemical, Ann Arbor, USA), diluted in PAD reaction buffer containing $10 \mathrm{mM} \mathrm{CaCl}_{2}$, were applied. The samples were incubated for $20 \mathrm{~h}$ at $37^{\circ} \mathrm{C}$. Plates were blocked in $100 \mu \mathrm{L} /$ well of blocking solution ( $2 \%$ BSA in $1 \times$ PBST) at room temperature for $1 \mathrm{~h}$. After incubation with blocking buffer, an anti-human citrullinated histone 3 primary 
antibody (1:2000, ab5103; Abcam, Cambridge, UK) and anti-rabbit IgG-Fc HRPconjugated secondary antibody were used to detect citrullinated proteins (1:7000). Subsequently, $100 \mu \mathrm{L}$ of 3,3',5,5'-tetramethylbenzidine (TMB) (Sigma-Aldrich, Milan, Italy) was added to each well. The amplification of the signal by HRP was given by the blue color obtained after $30 \mathrm{~min}$ of incubation, which changed to yellow once stopped by the addition of $1 \mathrm{~N} \mathrm{HCl}$. The optical density (OD) was measured at 450-620 nm using a Victor X3 Multilabel Reader (Perkin Elmer, Waltham, MA, USA; wallac 1420 work station software $)^{54,55}$.

Construction of promoter-reporter plasmids. The 5'-flanking region of PADI2 was generated by PCR using Q5 High-Fidelity DNA polymerase (New England Biolabs, Ipswich, USA), pLightSwitch_Prom PADI2 (Active Motif, La Hulpe, Belgium), as the template, and the primers listed in Supplementary Table 3. The thermocycler (Biorad C1000 Touch Thermal Cycler) settings consisted of $30 \mathrm{~s}$ of incubation at $98^{\circ} \mathrm{C}$, followed by 35 cycles at $98^{\circ} \mathrm{C}$ for $10 \mathrm{~s}, 30 \mathrm{~s}$ at the predicted melting temperature and $30 \mathrm{~s}$ at $72{ }^{\circ} \mathrm{C}$, and a final extension for $2 \mathrm{~min}$ at $72{ }^{\circ} \mathrm{C}$. The 5 '-flanking region of PADI4 was amplified by PCR using human genomic DNA from HFFs, as the template, and the primers listed in Supplementary Table 2. The PCR condition was an initial denaturation for 2 min at $95^{\circ} \mathrm{C}, 35$ cycles $\left(95^{\circ} \mathrm{C}\right.$ for $30 \mathrm{~s}, 56^{\circ} \mathrm{C}$ for $30 \mathrm{~s}$, and $72^{\circ} \mathrm{C}$ for $4 \mathrm{~min}$ ) and a final extension at $72^{\circ} \mathrm{C}$ for $8 \mathrm{~min}$. The resulting amplification products were digested with XhoI (Thermo Fisher Scientific, Waltham, USA) and HindIII (Thermo Fisher Scientific, Waltham, USA) and cloned into the pGL4.20[luc2/Puro] Vector (Promega, Madison, USA), which encodes the luciferase reporter gene luc2 (Photinus pyralis), but no regulatory elements. All of the constructs were prepared using the PureYield Plasmid Miniprep System (Promega, Madison, USA) and verified by restriction mapping and complete sequencing. The resulting chromatograms were analyzed using Chromas software 2.6.6 (Technolysium Ltd.).

Luciferase assay. HFFs were electroporated using a Micro-Porator MP-100 (Thermo Fischer Scientific, Waltham, USA), according to the manufacturer's instructions (a single $1300 \mathrm{~V}$ pulse, 30-ms pulse width). Briefly, $500 \mathrm{ng}$ of each construct were used every $2 \times 10^{5}$ cells, which were plated in 24 -well tissue culture clusters at a density of $2 \times 10^{5}$ cells/well. To correct for transfection efficiency, all cells were co-transfected with the pRL-SV40 vector (Promega, Madison, USA), which contained the Renilla luciferase gene driven by the SV40 promoter. After $24 \mathrm{~h}$, cells were infected with HCMV, UV-HCMV, or mock (MOI of $1 \mathrm{PFU} / \mathrm{ml}$ ). At $24 \mathrm{hpi}$, firefly and Renilla luciferase activities were measured using the DualLuciferase reporter assay system kit (Promega, Madison, USA) and a Victor X3 Multilabel Plate Reader (Perkin Elmer, Waltham, MA, USA; wallac 1420 work station software). Firefly luciferase activity from the luciferase reporter vector was normalized to the Renilla luciferase activity from the pRL-SV40 vector. Values were expressed as the ratio of relative light units (RLU) measured for firefly luciferase activity to the RLU measured for that of Renilla luciferase.

CRISPR-Cas9 vector constructs. The CRISPR/Cas9 system was employed to generate specific gene knockouts in HFFs. Briefly, a lentiviral CRISPR/Cas9 vector that encodes a codon-optimized nuclear-localized Cas9 gene N-terminally fused to the puromycin resistance gene via a T2A ribosome-skipping sequence was employed. This vector contains a human U6 promoter driving expression of a guide RNA (gRNA) consisting of a gene-specific CRISPR RNA (crRNA) fused to the trans-activating crRNA (tracrRNA) and a terminator sequence ${ }^{56}$. gRNA sequences are reported in Supplementary Table 4. An empty vector carrying no gRNA was used as negative control (WT cell line). All constructs were verified by Sanger sequencing (Chromas 2.6.6)

\section{Lentivirus production and transduction of HFFs with lentiviral CRISPR/Cas9.} Recombinant lentiviruses were packaged in HEK 293T cells by cotransfection of the 3rd Generation Packaging System Mix (kindly provided by A. Follenzi, University of Eastern Piedmont, Novara, Italy) with the above mentioned vectors to produce viral particles using Lipofectamine 2000 (Thermo Fisher Scientific, Waltham, USA). Viral supernatants were harvested after $72 \mathrm{~h}$ and used to transduce HFFs by infection in the presence of $8 \mu \mathrm{g} / \mathrm{ml}$ polybrene. Transduced cells were selected with puromycin $(1 \mu \mathrm{g} / \mathrm{ml})$ over the course of 14-day post transduction. After selection, successful knockout was confirmed using immunoblotting and TIDE analysis.

TIDE. After selection, successful knockout was confirmed using immunoblotting In addition, indel frequencies were quantified using TIDE ${ }^{57}$. Genomic DNA was extracted, and PCR amplicons spanning the single-guide RNA (sgRNA) target site were generated. The purified PCR products were then Sanger sequenced, and indel frequencies were quantified using the TIDE software (http://tide.nki.nl) (Supplementary Fig. 3). A reference sequence (wild-type cells) was used as a control. Genomic DNA was isolated from $1 \times 10^{6}$ cells using the ISOLATE II Genomic DNA Kit (Bioline Meridian Biosciences, Paris, France). PCR reactions were carried out with $50 \mathrm{ng}$ of genomic DNA and Q5 High-Fidelity DNA polymerase according to the manufacturer's instructions. PCR conditions were $30 \mathrm{~s}$ at $98^{\circ} \mathrm{C}(1 \mathrm{cycle})$, followed by $10 \mathrm{~s}$ at $98^{\circ} \mathrm{C}, 30 \mathrm{~s}$ at $5^{\circ} \mathrm{C}$ and $30 \mathrm{~s}$ at $72^{\circ} \mathrm{C}$ (35 cycles) (Biorad $\mathrm{C} 1000$ thermocycler). The PCR products were purified using the GeneJET Gel Extraction and DNA Cleanup Micro Kit (Thermo Fischer Scientific, Waltham, USA). The primer pairs spanning the target site are reported in Supplementary Table 5.

Pull down. Uninfected or HCMV-infected cells (MOI of $1 \mathrm{PFU} / \mathrm{ml}$ ) were washed with $1 \times$ PBS and lysed in radioimmunoprecipitation assay (RIPA) buffer $(50 \mathrm{mM}$ Tris pH 7.4; $150 \mathrm{mM} \mathrm{NaCl} 1 \mathrm{mM}$ EDTA; $1 \%$ nonidet P-40; $0.1 \%$ SDS; $0.5 \%$ deoxycholate; protease inhibitors). Proteins $(200 \mu \mathrm{g})$ were then incubated with $2 \mu \mathrm{g}$ of F95 antibody or with an isotype antibody as negative control (62-6820; Thermo Fischer Scientific, Waltham, USA) for $1 \mathrm{~h}$ at room temperature with rotation followed by overnight incubation at $4^{\circ} \mathrm{C}$ with protein G-Sepharose (Sigma-Aldrich, Milan, Italy). Immune complexes were collected by centrifugation and washed with RIPA buffer. The Sepharose beads were pelleted and washed three times with RIPA buffer, resuspended in reducing sample buffer $(50 \mathrm{mM}$ Tris $\mathrm{pH} 6.8 ; 10 \%$ glycerol $2 \%$ SDS; $1 \%$ 2-mercaptoethanol), boiled for $5 \mathrm{~min}$, and resolved on a SDS-PAGE gel to assess protein binding by immunoblotting.

\section{Citrullinome analysis by mass spectrometry: sample preparation. Sample} preparation in technical triplicates followed the procedure outlined in ref. ${ }^{58}$. Equal amounts of cell lysates from each experimental group $(300 \mu \mathrm{g})$ were diluted in buffer (100 mM HEPES $\mathrm{pH}$ 7.6) to a final concentration of $1 \mu \mathrm{g} / \mu \mathrm{L}$ and incubated with $20 \%$ trichloroacetic acid (TCA) and $0.5 \mathrm{mM}$ biotin- $\mathrm{PG}^{59}$ for $30 \mathrm{~min}$ at $37^{\circ} \mathrm{C}$ Labeled proteomes were precipitated on ice for $30 \mathrm{~min}$. Samples were pelleted through tabletop centrifugation $(21,100 \times \mathrm{g}, 15 \mathrm{~min})$ at $4{ }^{\circ} \mathrm{C}$. The supernatants were discarded, and the pellets were washed with cold acetone $(300 \mu \mathrm{L})$. After drying for $5 \mathrm{~min}$, the pellets were resuspended in 1.2\% SDS in PBS by bath sonication and heating. Samples were then transferred to $15-\mathrm{mL}$ screw-cap tubes and diluted in $1 \times$ PBS to a $0.2 \%$ SDS final concentration. Samples were incubated with streptavidin agarose slurry (Sigma-Aldrich, $170 \mu \mathrm{L}$ ) overnight at $4^{\circ} \mathrm{C}$ and for an additional $3 \mathrm{~h}$ at $25^{\circ} \mathrm{C}$. After discarding the flow-through, the streptavidin beads were washed with $0.2 \%$ SDS in PBS $(5 \mathrm{~mL})$ for $10 \mathrm{~min}$ at $25^{\circ} \mathrm{C}$. The beads were then washed three times with 1X PBS $(5 \mathrm{~mL})$ and three times with water $(5 \mathrm{~mL})$ in order to remove any unbound proteins. Beads were then transferred to a screw-cap microcentrifuge tube and heated in $1 \times$ PBS with $500 \mu \mathrm{L} 6 \mathrm{M}$ urea and $10 \mathrm{mM}$ DTT $\left(65^{\circ} \mathrm{C}, 20 \mathrm{~min}\right)$. Proteins bound to the beads were then alkylated with iodoacetamide $\left(20 \mathrm{mM}, 37^{\circ} \mathrm{C}\right.$ for $\left.30 \mathrm{~min}\right)$. The beads were successively pelleted by centrifugation $(1400 \times g$ for $3 \mathrm{~min})$ and the supernatant was removed. The pellet was resuspended in a premixed solution of $2 \mathrm{M}$ urea, $1 \mathrm{mM} \mathrm{CaCl}$, and $2 \mu \mathrm{g}$ Trypsin Gold (Promega, Madison, USA) in PBS. These were shaken overnight at $37^{\circ} \mathrm{C}$. The supernatant was collected and the beads were washed twice with water $(50 \mu \mathrm{L})$, each time collecting the supernatant. The fractions were combined, acidified with formic acid (5\% final concentration), and stored at $-20^{\circ} \mathrm{C}$ until use.

Mass spectrometry. Liquid chromatography-mass spectrometry/mass spectrometry (LC-MS/MS) analysis was performed with an LTQ-Orbitrap Discovery mass spectrometer (Thermo Fisher Scientific, Waltham, MA, USA) coupled to an EasynLC HPLC (Thermo Fisher Scientific, Waltham, MA, USA). Samples were pressure-loaded onto a $250-\mu \mathrm{m}$ fused-silica capillary hand-packed with $4 \mathrm{~cm}$ Aqua C18 reverse-phase resin (Phenomenex). Samples were separated on a hand-packed $100-\mu \mathrm{m}$ fused-silica capillary column with a $5-\mu \mathrm{m}$ tip packed with $10 \mathrm{~cm}$ Aqua C18 reverse-phase resin (Phenomenex). Peptides were eluted using a 10-h gradient of $0-100 \%$ Buffer B in Buffer A (Buffer A: $95 \%$ water, $5 \%$ acetonitrile, $0.1 \%$ formic acid; Buffer B: $20 \%$ water, $80 \%$ acetonitrile, $0.1 \%$ formic acid). The flow rate through the column was set to $\sim 400 \mathrm{~nL} / \mathrm{min}$, and the spray voltage was set to $2.5 \mathrm{kV}$. One full MS scan (FTMS) was followed by seven data-dependent MS2 scans (ITMS) of the $n$th most abundant ions. The tandem MS data were searched by the SEQUEST algorithm using a concatenated target/decoy variant of the human and viral UniProt database. A static modification of +57.02146 on cysteine was specified to account for alkylation by iodoacetamide. SEQUEST output files were filtered using DTASelect 2.0.

\section{Reductive dimethylation (ReDiMe) labeling and mass spectrometry for the} citrullinome analysis of wtAD169 and AD169DIE1-infected cells. The trypsin digest was desalted using Pierce C18 spin column (catalog No 89870) according to the manufacturer's protocol and was resuspended in $200 \mu \mathrm{L}$ of $100 \mathrm{mM}$ triethylammonium bicarbonate, $\mathrm{pH}$ 8.5. $20 \% \mathrm{H}^{12} \mathrm{CHO}(4 \mu \mathrm{L}$, light formaldehyde), $\mathrm{D}^{12} \mathrm{CDO}\left(4 \mu \mathrm{L}\right.$, medium formaldehyde), and $\mathrm{D}^{13} \mathrm{CDO}(4 \mu \mathrm{L}$, heavy formaldehyde $)$ were added to the mock, AD169- and AD169 $\triangle \mathrm{IE} 1$-infected samples, respectively. In total, $20 \mu \mathrm{L}$ of $0.6 \mathrm{M}$ sodium cyanoborohydride $\left(\mathrm{NaBH}_{3} \mathrm{CN}\right)$ was then added to both the mock and AD169-infected samples, respectively, while $20 \mu \mathrm{L}$ of $0.6 \mathrm{M}$ sodium cyanoborodeuteride $\left(\mathrm{NaBD}_{3} \mathrm{CN}\right)$ was added to the AD169 $\triangle \mathrm{IE} 1$-infected samples. The samples were incubated at room temperature for $2 \mathrm{~h}$. The samples were then cooled on ice and the reaction quenched with $4 \mu \mathrm{L}$ of $20 \%$ ammonium hydroxide. Formic acid $(8 \mu \mathrm{L})$ was then added to the samples. Heavy, medium, and light formaldehyde-labeled samples were mixed together, and the mixture was desalted and stored at $-20^{\circ} \mathrm{C}$ for proteomic analysis. Data was acquired using a NanoAcquity UPLC (Waters Corporation, Milford, MA) coupled to an Orbitrap Fusion Lumos Tribrid (Thermo Fisher Scientific, Waltham, MA) mass spectrometer. Peptides were trapped and separated using an in-house $100 \mu \mathrm{m}$ I.D. fusedsilica pre-column (Kasil frit) packed with $2 \mathrm{~cm}$ ProntoSil (Bischoff 
Chromatography, DE) C18 AQ (200, $5 \mu \mathrm{m})$ media and configured to an in-house packed $75 \mu \mathrm{m}$ I.D. fused-silica analytical column (gravity-pulled tip) packed with $25 \mathrm{~cm}$ Magic (Bruker, Billerica, MA) C18-AQ (100, $3 \mu \mathrm{m})$ media, respectively. Mobile phase A was water supplemented with $0.1 \%$ (v/v) formic acid, and mobile phase B was acetonitrile supplemented with $0.1 \%(\mathrm{v} / \mathrm{v})$ formic acid. Following a $3.8 \mu \mathrm{L}$ of sample injection, peptides were trapped at flow rate of $4 \mu \mathrm{L} / \mathrm{min}$ with $5 \%$ B for $4 \mathrm{~min}$, followed by gradient elution at a flow rate of $300 \mathrm{~nL} / \mathrm{min}$ from 5 to $35 \%$ B over $120 \mathrm{~min}$ (total run time $145 \mathrm{~min}$ ). Electrospray voltage was delivered by a liquid junction electrode $(1.5 \mathrm{kV})$ located between the columns and the transfer capillary to the mass spectrometer was maintained at $275^{\circ} \mathrm{C}$. Mass spectra were acquired over $\mathrm{m} / \mathrm{z} 375-1500 \mathrm{Da}$ with a resolution of $120,000(\mathrm{~m} / \mathrm{z} 200)$, a maximum injection time of $110 \mathrm{~ms}$, and an AGC target of 400,000. Tandem mass spectra were acquired using data-dependent acquisition ( $3 \mathrm{~s} \mathrm{cycle)}$ with an isolation width of 1.6 Da, HCD collision energy of $30 \%$, resolution of $15,000(\mathrm{~m} / \mathrm{z} 200)$, maximum injection time of $50 \mathrm{~ms}$, and an AGC target of 50,000.

Database search. Raw data were processed and searched using Maxquant 1.6.14 and its integrated Andromeda search engine using the Swiss-Prot human (downloaded 04/09/2019) and Uniprot HCMV (downloaded 02/27/2021). Search parameters were as follows: tryptic digestion with up to 2 missed cleavages; peptide $\mathrm{N}$ terminal acetylation, methionine oxidation, $\mathrm{N}$-terminal glutamine to pyroglutamate conversion were specified as variable modifications. The monoisotopic mass increment of the triplex dimethyl labels, light, medium, and heavy dimethyl labels at $28.0313,32.0564$, and $36.0757 \mathrm{Da}$, respectively, were set as a variable modification on the peptide $\mathrm{N}$-termini and lysine residues. Carbamidomethylation of cysteines was set as static modification. The main search tolerance was $6 \mathrm{ppm}$, and the first search tolerance was $50 \mathrm{ppm}$. Both the protein and peptides identification false discovery rates (FDR) were $<1 \%$. Protein grouping, dimethyl ratio calculations, and downstream statistics were performed in Scaffold Q + S 4.8.9 (Proteome Software, Portland, OR).

siRNA-mediated knockdown. HFFs were transiently transfected with a MicroPorator (Digital Bio Pharm, London, Great Britain) according to the manufacturer's instructions $(1200 \mathrm{~V}, 30 \mathrm{~ms}$ pulse width, one impulse) with a pool of small interfering RNAs (Qiagen, Hilden, Germany) targeting Mx1 (siMx1, FlexiTube siRNAs cat. Nos.: SI02781093, SI05459538, SI04435963, SI04435956), PAD2 (siPAD2, FlexiTube siRNAs cat. Nos.: SI04278953, SI04255860, SI04188793, SI00676872), PAD4 (siPAD4, FlexiTube siRNAs cat. Nos.: SI04939032, SI04359530, SI04299288, SI00676907) or control siRNA (siCTRL, 1027292) as a negative control. For siRNA-mediated knockdown of IFIT1, siRNA approach was performed according to Pichlmair et al. (siIFIT1_1: CTCCTTGGGTCGTTCTA CAAA; silFIT1_2: TACATGGGAGTTATCCATTGA) ${ }^{34}$.

Recombinant adenoviral vector production. The adenovirus-derived vectors (AdVs) expressing IFIT1 and LacZ were generated by means of a replacement strategy using recombineering methods, as described previously ${ }^{60,61}$. The open reading frame (ORF) was amplified using a specific set of primers for each desired construct (Supplementary Table 6), and colonies were analyzed by PCR and sequencing (Supplementary Table 6). IFIT1 and LacZ expression was assessed by western blotting using a V5 antibody. For cell transduction, HFFs were incubated with AdVIFIT1 at an MOI of 10 in DMEM. After $2 \mathrm{~h}$ at $37^{\circ} \mathrm{C}$, the virus was washed off, and fresh medium was applied. At $24 \mathrm{hpt}$, HFFs were infected with HCMV strain Merlin at an MOI of 1 and incubated for $144 \mathrm{~h}$.

UL54 and UL44 production and in vitro citrullination. Glutathione-S-transferase (GST) tagged UL54 was produced as described ${ }^{62}$ and was kindly provided by Han Chen. UL44 $\triangle$ C290 was produced as described ${ }^{63}$ with several modifications: after resuspension, cells were lysed by sonication at an amplitude of $40 \%$ for a total of $\sim 15 \mathrm{~min}$, pulsing in cycles of $5 \mathrm{~s}$ on and $9 \mathrm{~s}$ off. The lysate was centrifuged at $18,000 \times g$ for $1.5 \mathrm{~h}$ at $4^{\circ} \mathrm{C}$, then applied to a glutathione-Sepharose 4 FastFlow column (GE Healthcare) that had been equilibrated in buffer A ( $50 \mathrm{mM}$ Tris- $\mathrm{HCl}$ (pH 7.5), $10 \mathrm{mM}$ EDTA, $2 \mathrm{mM}$ dithiothreitol (DTT), $500 \mathrm{mM} \mathrm{NaCl}, 20 \%$ glycerol), and then washed extensively with the same buffer. UL44 $\Delta$ C 290 was eluted with buffer B (Buffer A $+15 \mathrm{mM}$ glutathione), and fractions containing the protein were combined and diluted 1.5:1 with buffer C (50 mM Tris- $\mathrm{HCl}[\mathrm{pH} 7.5], 1 \mathrm{mM}$ EDTA, $2 \mathrm{mM}$ DTT, $10 \%$ glycerol). To cleave off the GST tag, the sample was treated with HRV $3 \mathrm{C}$ protease (Takara) overnight at $4{ }^{\circ} \mathrm{C}$, loaded onto a heparin agarose column (Protein Ark), and eluted with a linear gradient of $150-1000 \mathrm{mM}$ $\mathrm{NaCl}$ in buffer C. Fractions containing UL44 $\triangle \mathrm{C} 290$ were combined and applied to a HiLoad ${ }^{\oplus}$ Superdex 200 column (GE Healthcare) in storage buffer (50 mM Tris$\mathrm{HCl}$ (pH 7.4), $0.1 \mathrm{mM}$ EDTA, $2 \mathrm{mM}$ DTT, $500 \mathrm{mM} \mathrm{NaCl}, 20 \%$ Glycerol). Fractions containing UL44 $\Delta \mathrm{C} 290$ were combined, concentrated using an Amicon ${ }^{\circ}$ Ultra-15 Centrifugal Filter Device (Merck Millipore, Milan), and stored in aliquots at $-80^{\circ} \mathrm{C}$.

In vitro citrullination of UL44 was performed as follows: $6 \mu \mathrm{M}$ UL44 $\Delta$ C290 was incubated in PAD assay buffer (50 mM HEPES, pH 7.6, $10 \mathrm{mM} \mathrm{CaCl}_{2}, 150 \mathrm{mM}$ $\mathrm{NaCl}, 2 \mathrm{mM}$ DTT, $12.5 \%$ glycerol for UL44) with recombinant human PAD2 or PAD4 (Chemical Cayman) at a concentration of $0.7 \mu \mathrm{M}$ for $180 \mathrm{~min}$, at $37^{\circ} \mathrm{C}$. Citrullination was terminated by the addition of $0.05 \mathrm{M}$ EDTA. As a control, a reaction was performed without PAD enzymes (mock treatment). Samples were purified on a Superose 6 Increase GL column (GE Healthcare) in $50 \mathrm{mM}$ Tris- $\mathrm{HCl}$ [pH 7.5], $1 \mathrm{mM}$ EDTA, $2 \mathrm{mM}$ DTT, $150 \mathrm{mM} \mathrm{NaCl}, 10 \%$ glycerol, to remove the vast majority of the PAD enzymes. Fractions from each reaction containing UL44 $\Delta$ C290 were concentrated using an Amicon ${ }^{\circledR}$ Ultra-15 Centrifugal Filter Device (Merck Millipore, Milan), and stored at $-20^{\circ} \mathrm{C}$. In order to estimate the amount of residual PAD enzymes, $2.2 \mu \mathrm{g}$ of each UL44 $\Delta \mathrm{C} 290$ sample was applied to SDS-PAGE, stained with Coomassie brilliant blue, and bands corresponding to PAD2 or PAD4 contamination were quantified relative to known amounts of PAD2 and PAD4 (Image Lab).

Production of recombinant human IFIT1 and in vitro citrullination. Recombinant IFIT proteins were expressed in E. coli and were purified on a HisTrap HP column (GE Healthcare, Chicago, IL, Stati Uniti).

The in vitro citrullination of IFIT1 was performed as previously described for UL44.

LC-MS/MS analysis of mock- or PAD2-treated recombinant IFIT1. One $\mu \mathrm{g}$ of recombinant IFIT1, mock or PAD2-treated, was digested with 1:50 LysC (Wako \#129-02541) overnight at $37^{\circ} \mathrm{C}$. Peptides were purified and concentrated on stage tips with three C18 Empore filter discs ( $3 \mathrm{M})$, and further measured via LC-MS/ MS, using an EASY- nLC 1200 system (Thermo Fisher Scientific, Waltham, MA, USA) coupled to a Q-Exactive HF mass spectrometer (Thermo Fisher Scientific, Waltham, MA, USA), on a $20-\mathrm{cm}$ reverse-phase analytical column $(75 \mu \mathrm{m}$ column diameter; ReproSil-Pur C18-AQ 1.9- $\mu \mathrm{m}$ resin; Dr. Maisch) and separated using a 60 min acetonitrile gradient. Raw files were processed using MaxQuant version 1.6.0.15 with carbamidomethyl (Cys) as fixed modification as well as oxidation (Met), Acetyl (Protein N-term) and citrullination (R), as defined by $\mathrm{H}(-1) \mathrm{N}(-1) \mathrm{O}$, as variable modifications.

In vitro transcription 7SK 5'-PPP-RNA and gel shift assay. Non-coding RNA (7SK anti-sense 356 bp) was transcribed in vitro using the SP6 MEGAscript kit (Thermo Fisher Scientific, Waltham, MA, USA)) as per the manufacturer's instruction ${ }^{64}$. In all, $50 \mathrm{nM}$ (5 pmol) of in vitro transcribed 7SK 5'-ppp-RNA was incubated with $5 \mu \mathrm{M}$ of recombinant IFIT1, either mock or treated with PAD2 for $3 \mathrm{~h}$, for $30 \mathrm{~min}$ at room temperature in PBS $-400 \mathrm{mM}$ DTT $-100 \mathrm{mM} \mathrm{NaCl}$, and loaded on a $0.8 \%$ Tris-Glycine agarose gel. The gel was stained in a $3 \times$ Gel Red (Biotium, \#41003) solution before imaging.

Functional assay of UL44. Long-chain DNA synthesis by UL54 and UL44 on a poly(dA)-oligo $(\mathrm{dT})_{12-18}$ primer template (Amersham Biosciences, Little Chalfont, UK) with radiolabeled [ $\left.{ }^{32} \mathrm{P}\right] \mathrm{dTTP}(\sim 55 \mathrm{Ci} / \mathrm{mmol})$ as a substrate was measured using a modification of a gel-based assay described previously ${ }^{38}$. Reactions contained $50 \mathrm{mM}$ TRIS- $\mathrm{HCl}$ [pH 7.5], $100 \mathrm{mM}\left(\mathrm{NH}_{4}\right)_{2} \mathrm{SO}_{4}, 3 \mathrm{mM} \mathrm{MgCl}, 0.1 \mathrm{mM}$ EDTA, $1 \mathrm{mM}$ DTT, 4 \% Glycerol, $40 \mu \mathrm{g} / \mathrm{mL}$ BSA, and using $26.5 \mathrm{nM}$ GST-UL54 alone or with $58 \mathrm{nM}$ of untreated UL44 $\triangle \mathrm{C} 290$ (UNT control), or with PAD2treated UL44 $\Delta$ C290, PAD4-treated UL44 $\Delta$ C290, or mock-treated UL44 $\Delta$ C290. To control for any effects of trace amounts of PAD enzymes contaminating UL44 $\triangle \mathrm{C} 290$ purified from citrullination reactions, in separate mixtures UNT control reactions were supplemented with $270 \mathrm{pM}$ PAD2 or $370 \mathrm{pM}$ PAD4. Gels with incorporated radioactivity were exposed to phosphorescence screens that were scanned with a Typhoon scanner (Amersham Biosciences, Little Chalfont, UK) and quantified using Image Lab. Data were normalized in each experiment by setting the UNT control as $100 \%$. Statistical analysis was performed by one-way analysis of variance (ANOVA) with Dunnett's correction using GraphPad Prism version 8.4.3 for Windows.

GO protein class. PANTHER (http://www.pantherdb.org) gene list analysis was used to functionally classify citrullinated proteins based on protein classes based on the UniProt ID code ${ }^{65}$.

Statistical analysis. All statistical tests and the IC50 were performed using GraphPad Prism version 5.00 or 8.4.3 for Windows (GraphPad Software, San Diego, USA). The data were presented as means \pm standard error of mean (SEM). Statistical significance was determined by using an unpaired $t$ test (two-tailed), oneway or two-way analysis of variance (ANOVA) with Bonferroni's, or Dunnett's post tests. Differences were considered statistically significant for $P<0.05\left({ }^{*} P<\right.$ $0.05 ; * * P<0.01 ; * * * P<0.001)$.

Reporting summary. Further information on research design is available in the Nature Research Reporting Summary linked to this article.

\section{Data availability}

The data that support the findings of this study are available within the paper and its supplementary information files. All other relevant data are available from the corresponding authors upon reasonable request. The mass spectrometry proteomics data have been deposited to the ProteomeXchange Consortium via the PRIDE [1] partner 
repository with the dataset identifier PXD025803, and PXD025818. Source data are provided with this paper.

Received: 7 October 2019; Accepted: 29 May 2021;

Published online: 23 June 2021

\section{References}

1. Griffiths, P., Baraniak, I. \& Reeves, M. The pathogenesis of human cytomegalovirus. J. Pathol. 235, 288-297 (2015).

2. Britt, W. J. Congenital human cytomegalovirus infection and the enigma of maternal immunity. J. Virol. 91, e02392-16 (2017).

3. Halenius, A. \& Hengel, H. Human cytomegalovirus and autoimmune disease. Biomed. Res. Int. 2014, 472978 (2014).

4. Soderberg-Naucler, C. Does cytomegalovirus play a causative role in the development of various inflammatory diseases and cancer? J. Intern. Med. 259, 219-246 (2006).

5. Du, Y., Zhang, G. \& Liu, Z. Human cytomegalovirus infection and coronary heart disease: a systematic review. Virol. J. 15, 31 (2018).

6. Jackson, S. E. et al. CMV immune evasion and manipulation of the immune system with aging. GeroScience 39, 273-291 (2017).

7. Cobbs, C. S. Does valganciclovir have a role in glioblastoma therapy? Neuro. Oncol. 16, 330-331 (2014)

8. Herbein, G. The human cytomegalovirus, from oncomodulation to oncogenesis. Viruses 10, 408 (2018).

9. Baker, P. J. et al. Posttranslational modification as a critical determinant of cytoplasmic innate immune recognition. Physiol. Rev. 97, 1165-1209 (2017).

10. Gudmann, N. S., Hansen, N. U. B., Jensen, A. C. B., Karsdal, M. A. \& Siebuhr, A. S. Biological relevance of citrullinations: diagnostic, prognostic and therapeutic options. Autoimmunity 48, 73-79 (2015).

11. Bicker, K. L. \& Thompson, P. R. The protein arginine deiminases: structure, function, inhibition, and disease. Biopolymers 99, 155-163 (2013)

12. van Venrooij, W. J., van Beers, J. J. B. C. \& Pruijn, G. J. M. Anti-CCP antibodies: the past, the present and the future. Nat. Rev. Rheumatol. 7, 391-398 (2011).

13. Vossenaar, E. R. \& van Venrooij, W. J. Citrullinated proteins: sparks that may ignite the fire in rheumatoid arthritis. Arthritis Res. Ther. 6, 107 (2004).

14. Knight, J. S. et al. Peptidylarginine deiminase inhibition disrupts NET formation and protects against kidney, skin and vascular disease in lupusprone MRL/ lpr mice. Ann. Rheum. Dis. 74, 2199-2206 (2015).

15. Acharya, N. K. et al. Neuronal PAD4 expression and protein citrullination: possible role in production of autoantibodies associated with neurodegenerative disease. J. Autoimmun. 38, 369-380 (2012).

16. Yang, L., Tan, D. \& Piao, H. Myelin basic protein citrullination in multiple sclerosis: a potential therapeutic target for the pathology. Neurochem. Res. 41, 1845-1856 (2016).

17. Nicholas, A. P. Dual immunofluorescence study of citrullinated proteins in Parkinson diseased substantia nigra. Neurosci. Lett. 495, 26-29 (2011).

18. Yuzhalin, A. E. Citrullination in cancer. Cancer Res. 79, 1274-1284 (2019).

19. Sokolove, J. et al. Brief report: citrullination within the atherosclerotic plaque: a potential target for the anti-citrullinated protein antibody response in rheumatoid arthritis. Arthritis Rheum. 65, 1719-1724 (2013).

20. Casanova, V. et al. Citrullination alters the antiviral and immunomodulatory activities of the human cathelicidin LL-37 during rhinovirus infection. Front. Immunol. 11, 85 (2020).

21. Trier, N. H. et al. Antibodies to a strain-specific citrullinated Epstein-Barr virus peptide diagnoses rheumatoid arthritis. Sci. Rep. 8, 3684 (2018).

22. Pratesi, F. et al. Antibodies to a new viral citrullinated peptide, VCP2: fine specificity and correlation with anti-cyclic citrullinated peptide (CCP) and anti-VCP1 antibodies. Clin. Exp. Immunol. 164, 337-345 (2011).

23. Pratesi, F., Tommasi, C., Anzilotti, C., Chimenti, D. \& Migliorini, P. Deiminated Epstein-Barr virus nuclear antigen 1 is a target of anti-citrullinated protein antibodies in rheumatoid arthritis. Arthritis Rheum. 54, 733-741 (2006).

24. Arisan, E. D., Uysal-Onganer, P. \& Lange, S. Putative roles for peptidylarginine deiminases in COVID-19. Int. J. Mol. Sci. 21, 1-29 (2020)

25. Bicker, K. L., Subramanian, V., Chumanevich, A. A., Hofseth, L. J. \& Thompson, P. R. Seeing citrulline: development of a phenylglyoxal-based probe to visualize protein citrullination. J. Am. Chem. Soc. 134, 17015-17018 (2012).

26. Scherer, M. et al. Characterization of recombinant human cytomegaloviruses encoding IE1 mutants L174P and 1-382 reveals that viral targeting of PML bodies perturbs both intrinsic and innate immune responses. J. Virol. 90, 1190-1205 (2016)

27. Luo, Y., Knuckley, B., Lee, Y.-H., Stallcup, M. R. \& Thompson, P. R. A fluoroacetamidine-based inactivator of protein arginine deiminase 4: design, synthesis, and in vitro and in vivo evaluation. J. Am. Chem. Soc. 128, 1092-1093 (2006)

28. Fensterl, V. \& Sen, G. C. Interferon-induced ifit proteins: their role in viral pathogenesis. https://doi.org/10.1128/JVI.02744-14 (2015).

29. Li, D. \& Swaminathan, S. Human IFIT proteins inhibit lytic replication of KSHV: a new feed-forward loop in the innate immune system. PLoS Pathog. 15, e1007609 (2019).

30. Zhang, L. et al. Antiviral effects of IFIT1 in human cytomegalovirus-infected fetal astrocytes. J. Med. Virol. 89, 672-684 (2017).

31. Haller, O., Staeheli, P., Schwemmle, M. \& Kochs, G. Mx GTPases: dynamin like antiviral machines of innate immunity. Trends Microbiol. 23, 154-163 (2015).

32. Schilling, M. et al. Human MxB protein is a pan-herpesvirus restriction factor J. Virol. 92, JVI.01056-18 (2018).

33. Crameri, M. et al. $\mathrm{MxB}$ is an interferon-induced restriction factor of human herpesviruses. Nat. Commun. 9, 1980 (2018).

34. Pichlmair, A. et al. IFIT1 is an antiviral protein that recognizes $5^{\prime}$-triphosphate RNA. Nat. Immunol. 12, 624-630 (2011).

35. Abbas, Y. M. et al. Structure of human IFIT1 with capped RNA reveals adaptable mRNA binding and mechanisms for sensing N1 and N2 ribose 2'-O methylations. Proc. Natl Acad. Sci. USA 114, E2106-E2115 (2017).

36. Ertl, P. F. \& Powell, K. L. Physical and functional interaction of human cytomegalovirus DNA polymerase and its accessory protein (ICP36) expressed in insect cells. J. Virol. 66, 4126-4133 (1992).

37. Weiland, K. L., Oien, N. L., Homa, F. \& Wathen, M. W. Functional analysis of human cytomegalovirus polymerase accessory protein. Virus Res. 34, 191-206 (1994).

38. Loregian, A., Appleton, B. A., Hogle, J. M. \& Coen, D. M. Residues of human cytomegalovirus DNA polymerase catalytic subunit UL54 that are necessary and sufficient for interaction with the accessory protein UL44. J. Virol. 78, 158-167 (2004)

39. Shelef, M. A., Bennin, D. A., Mosher, D. F. \& Huttenlocher, A. Citrullination of fibronectin modulates synovial fibroblast behavior. Arthritis Res. Ther. 14, R240 (2012)

40. Tarcsa, E. et al. Protein unfolding by peptidylarginine deiminase: Substrate specificity and structural relationships of the natural substrates trichohyalin and filaggrin. J. Biol. Chem. 271, 30709-30716 (1996).

41. Barlow, P. G., Findlay, E. G., Currie, S. M. \& Davidson, D. J. Antiviral potential of cathelicidins. Future Microbiol. 9, 55-73 (2014).

42. Barlow, P. G. et al. Antiviral activity and increased host defense against influenza infection elicited by the human cathelicidin LL-37. PLoS ONE 6, e25333 (2011)

43. Currie, S. M. et al. The human cathelicidin LL-37 has antiviral activity against respiratory syncytial virus. PLoS ONE 8, 73659 (2013).

44. Wang, G., Mishra, B., Epand, R. F. \& Epand, R. M. High-quality 3D structures shine light on antibacterial, anti-biofilm and antiviral activities of human cathelicidin LL-37 and its fragments. Biochimica et. Biophysica ActaBiomembranes 1838, 2160-2172 (2014).

45. Martineau, A. R. et al. IFN- $\gamma$ - and TNF-independent vitamin D-inducible human suppression of mycobacteria: the role of cathelicidin LL-37. J. Immunol. 178, 7190-7198 (2007).

46. Kilsgård, O. et al. Peptidylarginine deiminases present in the airways during tobacco smoking and inflammation can citrullinate the host defense peptide LL37, resulting in altered activities. Am. J. Respir. Cell Mol. Biol. 46, 240-248 (2012)

47. Gariano, G. R. et al. The intracellular DNA sensor IFI16 gene acts as restriction factor for human cytomegalovirus replication. PLoS Pathog. 8, e1002498 (2012).

48. Luganini, A., Caposio, P., Landolfo, S. \& Gribaudo, G. Phosphorothioatemodified oligodeoxynucleotides inhibit human cytomegalovirus replication by blocking virus entry. Antimicrob. Agents Chemother. 52, 1111-1120 (2008).

49. Bon, I. et al. Peptide-derivatized SB105-A10 dendrimer inhibits the infectivity of R5 and X4 HIV-1 strains in primary PBMCs and cervicovaginal histocultures. PLoS ONE 8, e76482 (2013).

50. Pignoloni, B. et al. Distinct roles for human cytomegalovirus immediate early proteins IE1 and IE2 in the transcriptional regulation of MICA and PVR/ CD155 expression. J. Immunol. 197, 4066-4078 (2016).

51. E, X. et al. An E2F1-Mediated DNA damage response contributes to the replication of human cytomegalovirus. PLoS Pathog. 7, e1001342 (2011)

52. Pauwels, R. et al. Rapid and automated tetrazolium-based colorimetric assay for the detection of anti-HIV compounds. J. Virol. Methods 20, 309-321 (1988).

53. Dell'Oste, V. et al. Innate nuclear sensor IFI16 translocates into the cytoplasm during the early stage of in vitro human cytomegalovirus infection and is entrapped in the egressing virions during the late stage. J. Virol. 88, 6970-6982 (2014).

54. Zendman, A. J. W. et al. ABAP: antibody-based assay for peptidylarginine deiminase activity. Anal. Biochem. 369, 232-240 (2007).

55. Damgaard, D., Senolt, L., Nielsen, M. F., Pruijn, G. J. \& Nielsen, C. H Demonstration of extracellular peptidylarginine deiminase (PAD) activity in 
synovial fluid of patients with rheumatoid arthritis using a novel assay for citrullination of fibrinogen. Arthritis Res. Ther. 16, 498 (2014).

56. van de Weijer, M. L. et al. A high-coverage shRNA screen identifies TMEM129 as an E3 ligase involved in ER-associated protein degradation. Nat. Commun. 5, 3832 (2014)

57. Brinkman, E. K., Chen, T., Amendola, M. \& van Steensel, B. Easy quantitative assessment of genome editing by sequence trace decomposition. Nucleic Acids Res. 42, e168 (2014).

58. Tilvawala, R. et al. The rheumatoid arthritis-associated citrullinome. Cell Chem. Biol. 25, 691-704.e6 (2018).

59. Lewallen, D. M. et al. Chemical proteomic platform to identify citrullinated proteins. ACS Chem. Biol. 10, 2520 (2015).

60. Biolatti, M. et al. Human cytomegalovirus tegument protein pp65 (pUL83) dampens type I interferon production by inactivating the DNA sensor cGAS without affecting STING. J. Virol. 92, e01774-17 (2018).

61. Chartier, C. et al. Efficient generation of recombinant adenovirus vectors by homologous recombination in Escherichia coli. J. Virol. 70, 4805-4810 (1996).

62. Chen, H., Beardsley, G. P. \& Coen, D. M. Mechanism of ganciclovir-induced chain termination revealed by resistant viral polymerase mutants with reduced exonuclease activity. Proc. Natl Acad. Sci. USA 111, 17462-17467 (2014).

63. Appleton, B. A., Loregian, A., Filman, D. J., Coen, D. M. \& Hogle, J. M. The cytomegalovirus DNA polymerase subunit UL44 forms a C clamp-shaped dimer. Mol. Cell 15, 233-244 (2004).

64. Pichlmair, A. et al. RIG-I-mediated antiviral responses to single-stranded RNA bearing 5'-phosphates. Science 314, 997-1001 (2006).

65. Mi, H., Muruganujan, A., Ebert, D., Huang, X. \& Thomas, P. D. PANTHER version 14: more genomes, a new PANTHER GO-slim and improvements in enrichment analysis tools. Nucleic Acids Res. 47, D419-D426 (2019).

\section{Acknowledgements}

We are grateful to Davide Gibellini for HIV FACS analysis, Han Chen for providing GST-UL54, and Jean Pesola for advice on statistical analysis. We thank Marcello Arsura for critically reviewing the manuscript. This research was supported by the European Commission under the Horizon2020 program (H2020-MSCA-ITN-2015) (S.L.), the Italian Ministry of Education, University and Research-MIUR (PRIN 20178ALPCM) (V. D.O.), "Cassa di Risparmio" Foundation of Turin ( $R F=2019.2273)$ (V.D.O.), the Compagnia San Paolo of Turin (IFIBD) (M.D.A.), the AGING Project-Department of Excellence-Department of Translational Medicine, University of Piemonte Orientale (G.G.) and the University of Turin (RILO1801) (RILO1901) (S.L.) (M.D.A.) (V.D.O.) (F G.) (M.B.). Work in the Thompson lab is funded by the National Institute of General Medical Sciences (R35GM118112) and National Institute of Health (F32GM128231). Work in the Coen lab was supported by the National Institute of Allergy and Infectious Diseases (R56AI019838 and R21AI141940). Work in the Pichlmair lab is funded by the ERC consolidator grant (ERC-CoG ProDAP, 817798) and the German Research Foundation (TRR179/TP11, TRR237/A07). Work in Stamminger lab is funded by the Deutsche Forschungsgemeinschaft (DFG) (STA357/7-1)

\section{Author contributions}

G.G., F.G., S.P., and S.L. conceived and designed the experiments. G.G., F.G., S.P., G.O., V.D.O., M.B., and V.G. performed the experiments and analyzed the data. A.J.S., P.R.T., E.W., S.M., and V.G. carried out the LC-MS/MS analyses. J.A.S. and R.J.L. supported the generation of the CRISPR/Cas9 KO cell lines. T.S. supported the design of the experiments with AD169AIE1. M.D.A., D.M.C., and A.P. critically revised the manuscript. All authors contributed to writing this manuscript.

\section{Competing interests}

The authors declare the following competing financial interest(s): P.R.T. founded Padlock Therapeutics and is entitled to payments from Bristol Myers Squibb if certain milestones are met. P.R.T. is a consultant for Celgene and Disarm Therapeutics. Italian Patent No. 102011596547852 issued in October 20, 2019 ("PAD2 PER USO NELLA PREVENZIONE E/O TRATTAMENTO O DIAGNOSI DI INFEZIONI DA VIRUS DELLA FAMIGLIA HERPESVIRIDAE").

\section{Additional information}

Supplementary information The online version contains supplementary material available at https://doi.org/10.1038/s41467-021-24178-6.

Correspondence and requests for materials should be addressed to M.D.A. or S.L.

Peer review information Nature Communications thanks the anonymous reviewers for their contribution to the peer review of this work.

Reprints and permission information is available at http://www.nature.com/reprints

Publisher's note Springer Nature remains neutral with regard to jurisdictional claims in published maps and institutional affiliations.

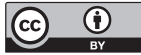

Open Access This article is licensed under a Creative Commons Attribution 4.0 International License, which permits use, sharing, adaptation, distribution and reproduction in any medium or format, as long as you give appropriate credit to the original author(s) and the source, provide a link to the Creative Commons license, and indicate if changes were made. The images or other third party material in this article are included in the article's Creative Commons license, unless indicated otherwise in a credit line to the material. If material is not included in the article's Creative Commons license and your intended use is not permitted by statutory regulation or exceeds the permitted use, you will need to obtain permission directly from the copyright holder. To view a copy of this license, visit http://creativecommons.org/ licenses/by/4.0/.

() The Author(s) 2021 